Int. J. Dev. Biol. 53: 303-322 (2009)

doi: $10.1387 / \mathrm{ijdb} .082675 \mathrm{av}$

\title{
The conserved role of sirtuins in chromatin regulation
}

\author{
ALEJANDRO VAQUERO* \\ Chromatin Biology Laboratory, Cancer Epigenetics and Biology Program (PEBC), \\ ICREA and Catalan Institute of Oncology (ICO)/IDiBELL, Barcelona, Spain
}

\begin{abstract}
The members of the Sir2 family, or Sirtuins, have garnered considerable attention because of their key roles as metabolic sensors and mediators of cell survival under stress. Sirtuins may play roles in myriad human pathologies such as cancer, neurological diseases, malaria, leishmaniasis and hormone-related disorders. They are present from prokaryotes to humans and show a high degree of functional diversification that has led to two different enzymatic activities, a wide range of substrates and a highly diversified pattern of cellular localization. Throughout chromatin evolution, Sirtuins have maintained an intimate functional relationship in regulating its structure and function via their targeting of histones, particularly H4K16Ac, as well as other nonhistone chromatin proteins. This link permitted fast communication from metabolic fluctuations to chromatin allowing efficient adaptation to environmental stimuli. Therefore, understanding the common path of Sirtuins and chromatin development over the course of evolution might be important for understanding not only the remarkable diversity of functions of these proteins in mammals, but also the path followed by chromatin evolution. Herein is provided an overview of current knowledge of Sirtuin function, from bacteria to humans, including a discussion on its implications for chromatin dynamics, organization and integrity.
\end{abstract}

KEY WORDS: sirtuins, chromatin, SirT1-7, deacetylase, heterochromatin

The remarkable size of eukaryotic genomes dictates that nuclear DNA be assembled into a compact - yet dynamic - structure that can efficiently store and correctly manage genetic information. Hence, DNA associates with histones into the nucleoproteic structure known as chromatin (Kornberg and Lorch, 1999). However, chromatin structure is not homogeneous; it is organized into a hierarchy of successive levels of compaction that range from the basic unit of chromatin, the nucleosome, to the most compacted form, the metaphase chromosome. Chromatin structure not only determines the physical distribution of the genome, but plays a key role in controlling access to genetic information and, therefore, to gene expression (Kornberg and Lorch, 1999; Wu and Grunstein, 2000). Thus, the first level of chromatin organization, the $11 \mathrm{~nm}$ fiber, corresponds to a nucleosome array or beads on a string, in which the DNA is compacted seven-fold. This fiber is accessible to the transcriptional machinery and is associated with transcriptionally active regions, which are also known as active chromatin or euchromatin (Trojer and Reinberg, 2007; Vaquero et al., 2003). In contrast to euchromatin, heterochromatin refers to the regions of the genome that associate to inactive regions, stain differentially with certain dyes, and correspond to a more com- pacted chromatin structure. The best candidate for heterochromatin structure, supported by numerous in vitro studies, is the 30$\mathrm{nm}$ fiber, which corresponds to a considerably more compacted (42-fold) DNA structure that is refractory to transcription. However, the $30 \mathrm{~nm}$ fiber, has still not been clearly detected in vivo (Tremethick, 2007; Trojer and Reinberg, 2007).

The transition between these two levels of chromatin organization is vital to the control of transcription, replication and many other cellular functions associated with DNA.

One of the major findings of the last decade is the fact that histones participate in virtually every aspect of chromatin regulation. A major mechanism by which histones mediate this regulation is the modification of their N-terminal domains, or histone tails, which are accessible, unstructured domains that protrude from nucleosomes. Certain residues in histone tails undergo specific post-translational modifications such as acetylation, methylation, phosphorylation, ADP-ribosylation, ubiquitination,

Abbreviations used in this paper: HDAC, histone deacetylase; HMT, histone methyltransferase; MEF, mouse embryonic fibroblast; Sir, silencing information regulator.

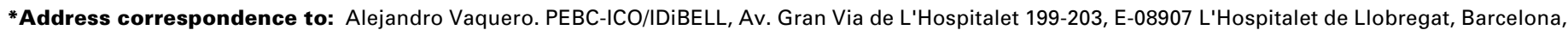
Spain. Fax: +34-93-260-7219. e-mails: avaquero@iconcologia.net ; alejandro.vaquero@icrea.es
} webs: http://www.icrea.es/ca/investigadors/index.html and http://www.pebc.cat

Published online: 2 April 2009

ISSN: Online 1696-3547, Print 0214-6282 
sumoylation, and biotinylation (Vaquero et al., 2003). Among these modifications, the acetylation and methylation of lysine residues in histones $\mathrm{H} 3$ and $\mathrm{H} 4$, are critical to the regulation of chromatin structure and gene expression (Shahbazian and Grunstein, 2007). The acetylation of lysine 16 in histone H4 (H4K16Ac) stands out for its involvement in epigenetic phenomena seen throughout chromatin evolution as well as for its unique role in chromatin structure, gene expression, DNA repair and recombination (Vaquero et al., 2007b). These post-translational modifications are partly epigenetic, meaning that organisms can pass them on to their progeny. Alteration of epigenetic processes has remarkable consequences for numerous human pathologies, including cancer (Esteller, 2007; Ting et al., 2006).

Histone marks have provided important information on the defining features of euchromatin and heterochromatin as well as on the factors involved in the transition between these two forms of chromatin (Vaquero et al., 2003). Overall, euchromatic active regions correlate with lysine acetylation and certain combinations of methylation in both lysine and arginine. These modifications provide regulatory factors with access to promoter regions and allow efficient transcription by RNA polymerase II (Eissenberg and Shilatifard, 2006). These marks are H4K16Ac, H3K4me3, H3K36me3, H3K79me2 and 3, and H4R3me2. In contrast, compacted heterochromatin regions are generally hypoacetylated and methylated in a discrete combination of lysine methylated marks such as H3K9me2 and 3, H4K20me1 and 3, and H3K27me3 (Trojer and Reinberg, 2007). In particular, methylation of lysine 9 in $\mathrm{H} 3$ (H3K9me2 and 3 ) is a hallmark of global chromatin organization, and its recognition by specific structural proteins such as HP1 is required for heterochromatin assembly and spreading (Lachner and Jenuwein, 2002).

Histone deacetylases (HDACs) are part of a group of proteins that regulate acetylation marks. These enzymes are responsible for removing the acetyl group from $\varepsilon$-lysine residues and, consequently, are involved in gene repression and heterochromatin formation. This role also makes HDACs key players in epigenetic regulation and management of specific spatial-temporal programs of expression, such as development and cellular differentiation (Ahringer, 2000; Margueron et al., 2005; Vaquero et al., 2003; Verdin et al., 2003). Moreover, HDACs have important roles in DNA repair, DNA replication, cell cycle control, apoptosis and other functions (de Ruijter et al., 2003; Kurdistani and Grunstein, 2003). Interestingly, HDACs are not restricted to histone deacetylation, but rather have a broad range of non-histone targets. Acetylation/ deacetylation of non-histone proteins has emerged as a more general mechanism for modulating cellular protein functions than previously anticipated. Currently available data suggest three main levels of regulation: DNA-binding, protein stability and enzymatic activity (Glozak et al., 2005).

HDACs have been divided into four phylogenetic groups (Class I to IV) (Yang and Seto, 2008). Classes I, II and IV are highly related from a structural and mechanistic point of view, whereas Class III comprises the members of the Sir2 family, a group of proteins with unique features crucial for cell fitness, adaptation to environmental stimuli and genomic integrity.

\section{The Sir2 family}

The Sir2 family is defined by its homology to the budding yeast silencing factor Sir2p (Silencing Information Regulator 2), an $\mathrm{NAD}^{+}$-dependent histone deacetylase (Imai et al., 2000; Landry et al., 2000) involved in processes that include epigenetic silencing, DNA repair, replication, recombination and cell cycle control (Saunders and Verdin, 2007; Vaquero et al., 2007b). The degree of conservation among Sir2 family members is restricted to the catalytic domain, a region of approximately 250 residues (Frye, 1999) that contains two well-defined structural motifs: an NAD+binding, reverse Rossman fold domain and a small zinc ribbon that provides structural stability (Finnin et al., 2001; Min et al., 2001).

Sir2 family members are characterized by their dependence on $\mathrm{NAD}^{+}$for conducting enzymatic reactions (Imai et al., 2000). The dinucleotide $\mathrm{NAD}^{+}$is a metabolic cofactor required for electron transfer in intermediary metabolism together with its reduced form, NADH. In the catalytic mechanism mediated by these enzymes, $\mathrm{NAD}^{+}$is catabolized into nicotinamide and ADP-ribose in the presence of an acetylated target (Sauve and Schramm, 2003). In contrast to the other classes of HDACs, Class III proteins do not release acetyl groups into solution as acetate. Instead, the acetyl groups are transferred to ADP-ribose, releasing O-acetylADP-ribose as final product (Sauve et al., 2001).

The fact that sirtuins require $\mathrm{NAD}^{+}$is fundamental to understanding most of their functions, since it suggests that they can act as sensors of a cell's metabolic state (Fulco et al., 2003; Haigis and Guarente, 2006). Hence, sirtuins are able to relay changes in metabolism to chromatin through deacetylation of histones and other proteins. As we will see, throughout evolution, there have been two primary functions associated with sirtuins: metabolism and chromatin regulation. A third role, stress response, is widely found in eukaryotes, but not to the extent of the former two, suggesting that it was acquired later in evolution.

The Sir2 family catalytic mechanism not only conducts deacetylation, but can also have mono ADP-ribosyltransferase activity (Tanny et al., 1999), which is present in almost all sirtuins tested to date-although in many, this is only residual (Saunders and Verdin, 2007; Yamamoto et al., 2007). Although Sirtuins were originally ribosyltransferases, the fact that they perform protein deacetylation in archaea as well as in bacteria suggests that they probably acquired this function relatively early in evolution (Starai et al., 2002; Tsang and Escalante-Semerena, 1998). The discovery of HDAC activity in Sir2 family proteins led to their immediate classification as HDAC Class III. However, not all sirtuins show detectable deacetylase activity (North et al., 2005). In some cases, they only exhibit mono-ADP ribosyltransferase activity. Therefore, the scientific community might want to reconsider the definition of Class III HDACs. Nonetheless, sirtuins lacking known deacetylase activity might actually be true deacetylases of unidentified substrates.

As mentioned before, the Sir2 family is much older than histones and chromatin. In fact, its members are found in all three life domains (eubacteria, archaea and eukaryotes) (Frye, 2000) and findings suggest that the original role of sirtuins was to regulate metabolism via key enzymes such as acetyl-CoA synthetase (Starai et al., 2002). However, the functional link between sirtuins and chromatin regulation is particularly striking for various reasons. First, sirtuins have been involved in chromatin regulation throughout evolution from the first examples of chromatin-like organization of DNA in archaea (Bell et al., 2002) to the more complex and developed mammalian genome (Kuzmichev et al., 


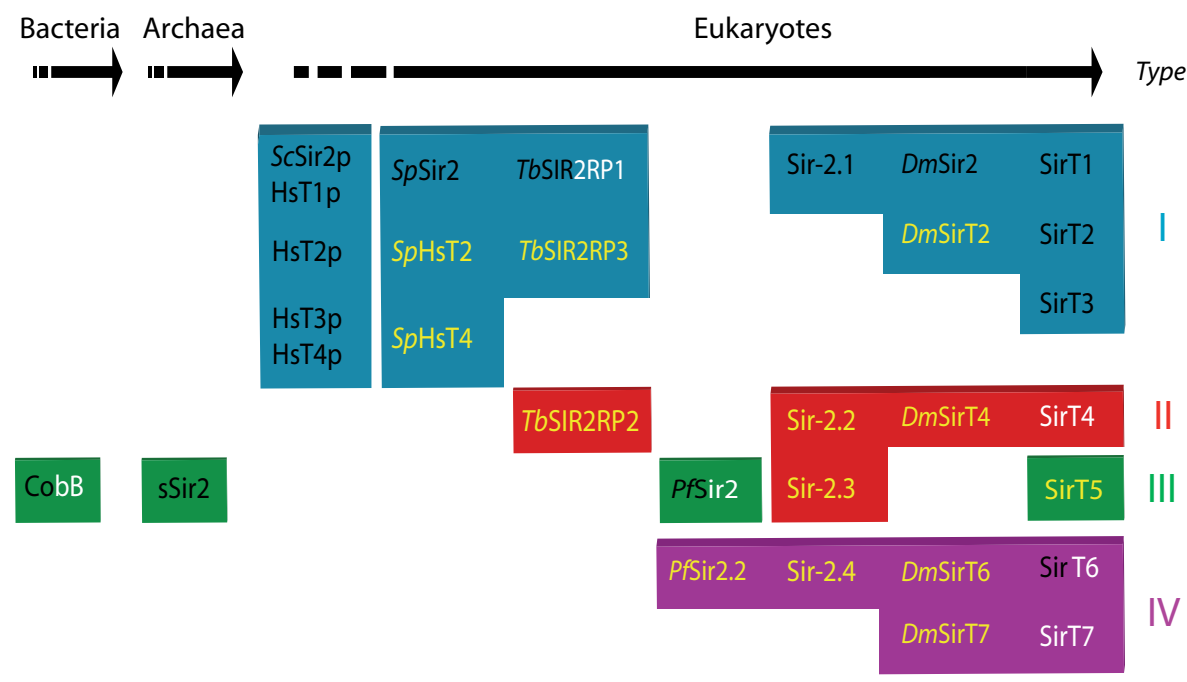

Salmonella Sulfolobus s.cerevisiae s.pombe Trypanosoma Plasmodium C.elegans Drosophila Mammals

Fig. 1. Classification of sirtuins. List of sirtuins from selected organisms from bacteria to humans classified phylogenetically (Type) according to Frye (2000). The denomination "Type" here and elsewhere in the text has been used instead of "Class", to avoid confusion with HDAC classification (HDAC Class I to III). The font color used for the sirtuins indicates current knowledge on their enzymatic activity: black for those with known deacetylase activity; white for those whose main activity is ADP-ribosylation; and black and white for both. The sirtuins shown in yellow have not yet been characterized; hence, no information on them is available.

2004; Vaquero et al., 2007a, Vaquero et al., 2004; Vaquero et al., 2006). Secondly, eukaryotic sirtuin activity is closely related to the regulation of a particular mark, H4K16Ac and, to a lesser extent, H3K9Ac (Vaquero et al., 2007b). Interestingly, these are the only two residues with a well-defined role in chromatin structure regulation (Shahbazian and Grunstein, 2007), which suggests that sirtuin specificity has closely evolved with the control of chromatin organization. Thirdly, sirtuin activity not only targets histones, but also various other chromatin-related factors such as chromatin modifying enzymes, structural proteins, and transcription factors (Saunders and Verdin, 2007; Shahbazian and Grunstein, 2007). Lastly, although the sirtuins of higher organisms are involved in diverse functions implying myriad targets, many of these roles are executed through gene expression, and therefore, through chromatin regulation.

Interestingly, sirtuin catalytic activity-in contrast to that of other HDACs - is tightly regulated by different mechanisms. One mechanism, found from yeast to man, is the non-competitive effect of excess free nicotinamide, which is released upon $\mathrm{NAD}^{+}$ catabolism (Bitterman et al., 2002). This inhibition could represent a way of limiting sirtuin activity and thereby avoiding $N A D^{+}$ depletion, which can prove lethal in certain conditions, as was shown for Poly-ribosyltransferase 1 (PARP1) (Pieper et al., 2000). A second mechanism involves the metabolic intermediary nicotinamide riboside, a $\mathrm{NAD}^{+}$precursor in the yeast salvage pathway that enhances Sir2 activity in vivo (Belenky et al., 2007). A third mechanism through which sirtuins are regulated involves 0 acetyl-ADP ribose, the main product of Sir2 activity. In the case of Sir3p, O-acetyl-ADP ribose binding has been shown to cause a conformational change that increases its binding to ScSir2p and promotes loading onto chromatin (Liou et al., 2005). However, the way in which O-acetyl-ADP ribose regulates the other mammalian sirtuins is unclear. The only available clue is that this molecule can bind to the histone macroH2A $(\mathrm{mH} 2 \mathrm{~A})$, an $\mathrm{H} 2 \mathrm{~A}$ variant involved in certain forms of heterochromatin (Kustatscher et al., 2005). Although this might suggest downstream signaling of sirtuin action, the effect of O-acetyl-ADP ribose on $\mathrm{mH} 2 \mathrm{~A}$ is unknown.

Metabolites are not the only type of molecule that can modulate sirtuin activity. Recent studies have identified several proteins that can enhance or inhibit the activity of certain sirtuins such as mammalian SirT1 (Kim et al., 2007; Kim et al., 2008; Zhao et al., 2008). However, the conditions in which these modulators act remain unknown.

An interesting consequence of sirtuin involvement in metabolic signaling is a possible link to lifespan control. This has been demonstrated in organisms including yeast, $C$. elegans and Drosophila (Longo and Kennedy, 2006; Rogina and Helfand, 2004; Tissenbaum and Guarente, 2001). Given that caloric restriction, which is associated with lifespan increase, induces sirtuin activity and expression, sirtuins have been speculated to be mediators of caloric restriction effects on longevity, perhaps through enhancing cell viability. This has only been demonstrated in yeast and Drosophila (Longo and Kennedy, 2006; Rogina et al., 2002), although data suggest that it might also the case in mammals (Boily et al., 2008).

The number of sirtuins varies among different organisms and generally correlates with greater complexity. For instance, prokaryotes have one to two sirtuins, yeast has three to five, Drosophila has five and mammals have seven (Fig. 1). However, plants are an exception to this rule: Arabidopsis thaliana and rice only contain two sirtuins (Frye, 2000).

Sirtuins have been phylogenetically divided into five types: I to IV, and U (Frye, 2000) (Fig. 1). Type I members are clearly linked to chromatin regulation-although not exclusively-and show true histone deacetylase activity. Type I sirtuins include all yeast sirtuins, human SirT1-3, and others. Type II comprises sirtuins of prokaryote origin that seem to be involved in metabolic control. These sirtuins seem to have a primary ADP-ribosyltransferase activity and are mainly located in the mitochondria. Type III is another prokaryote-related group of sirtuins; in fact, it includes the majority of eubacterial and archeal Sirtuins. The eukaryotic members are, like Type II sirtuins, located in the mitochondria. Type IV contains eukaryotic sirtuins that also appear to be functionally related to chromatin, such as mammalian SirT6 and SirT7. Although previous findings suggested that Type IV sirtuins were only ADP-ribosyltransferases, the very recent discovery of H3K9Ac-specific deacetylase activity for SirT6 in telomeres has changed the functional view of Class IV, and suggests that both activities coexist in this family (Michishita et al., 2008). Finally, Type $U$ contains other uncharacterized prokaryotic sirtuins. Strikingly, the most common combination of sirtuins present through evolution is of Types II and IV. Further studies should help 
elucidate the features of each type and determine how the different evolutionary lines developed.

\section{Prokaryotes}

Although sirtuins are widely distributed, they are not present in all prokaryotes. Current knowledge of bacterial Sir2-family members and their functions is quite limited. Sirtuins from Gramnegative bacteria are phylogenetically related to archaea members and have been shown to possess both ADP-ribosyltransferase and deacetylase activity (Starai et al., 2002; Tsang and EscalanteSemerena, 1998). In contrast, Gram-positive sirtuins are completely uncharacterized. The Salmonella enterica sirtuin encoded by $C o b B$ is involved in the regulation of acetyl-CoA synthetase (Acs), the enzyme that generates acetyl-CoenzymeA (Ac-CoA) from acetate, ATP and CoenzymeA (CoA) (Starai et al., 2002). Deacetylation of Acs lysine 609 by CobB results in a two-fold increase in Acs activity and allows Ac-CoA generation under growth conditions in which the carbon and energy sources are short-chain fatty acids (e.g. propionate and acetate). Additionally, CobB can compensate for the loss of CobT, a phosphoribosyltransferase involved in cobalamin (vitamin B12) synthesis (Tsang and Escalante-Semerena, 1998). These findings suggest that both activities have coexisted since the early development of the sirtuin family.

Archaea provide a complex and unique view of the early stages of chromatin evolution. Firstly, archaeal chromosomes contain two widely distributed groups of chromatin proteins: histones and Alba (Sandman and Reeve, 2005). Some members of the Euryarchaeota and Nanoarchaeota phyla contain histones that are packed into nucleosomes comprised of $80 \mathrm{bp}$ of DNA wrapped around a histone octamer (Sandman and Reeve, 2005). These histones contain the characteristic histone fold of eukaryotic histones and can form chromatin fibers in vitro similarly to eukaryotic histones, but they do not have exposed N-terminal tails nor do they undergo post-translational modifications (Luijsterburg et al., 2008). Alba, on the other hand, is more ubiquitous than histones: it is found in all archaea, with the exception of some Euryarchaeota (Sandman and Reeve, 2005). Some archaea contain both types of chromatin proteins, whereas others contain only one type, reflecting the evolution of different strategies to efficiently organize DNA. Interestingly, eukaryotes contain both histone and Alba proteins. However, eukaryotic histones evolved to acquire histone $\mathrm{N}$-terminals that undergo a wide range of post-translational modifications, whereas eukaryotic Alba relatives acquired a more specialized RNA-related role (Bernander, 2003)

Because Alba has been studied almost exclusively in Sulfolobus, which is a member of the Crenarchaea phylum, and therefore lacks histones, the degree of interplay between Alba and histones, and the possible implications of this interaction on DNA organization in other archaea, are poorly understood. Alba is a protein dimer formed by $10 \mathrm{kDa}$ subunits (Zhao et al., 2003). It nonspecifically binds to double-stranded DNA and is uniformly distributed across the genome. Consistent with a role as general chromatin structure component, Alba binds to DNA with a stoichiometry of 5-10 bp per protein dimer, creating a chromatin-like structure (Zhao et al., 2003). Like eukaryotic histones, Alba has an N-terminal domain that is acetylated at lysine 16 , which negatively affects Alba's binding affinity for DNA (Wardleworth et al., 2002). Interestingly, Sulfolobus Sir2 has been shown to increase Alba binding to DNA through deacetylation of K16, which results in the formation of a compact, chromatin-like structure that is refractory to transcription (Bell et al., 2002; Wardleworth et al., 2002). This is a remarkable finding, since it involves one of the earliest known stages of chromatin evolution. The functional involvement of Sir2 suggests not only that sirtuins have been involved in chromatin structure regulation from the very beginning, but also that Sir2 might be among the factors that have shaped chromatin evolution.

\section{Lower eukaryotes}

The transition from prokaryotes to eukaryotes was brought about by a revolution in many aspects, including the creation of the nuclear membrane, the development of new organelles and the organization of DNA into true chromatin. It is in lower eukaryotes that specialized chromatin machinery capable of efficient packing is first observed. This allowed the increase in genome size and complexity necessary for evolution of multicellular organisms, cell type differentiation and development.

There is actually a considerable amount of data on the role of sirtuins in lower eukaryotes. This has mainly come from genetic studies on the budding yeast Saccharomyces cerevisiae, in which the first sirtuin (ScSir2p) was identified (Rine and Herskowitz, 1987; Rine et al., 1979). Studies in lower eukaryotes generally implicate sirtuins in chromatin structure regulation. In fact, nuclear sirtuins have two conserved cellular localizations: telomeres and the nucleolus (Guarente, 2000). In both cases, sirtuins participate in heterochromatin formation. In the first, they play an important role in genome structure and gene silencing, whereas in the second, they mediate silencing of rDNA expression, cell cycle control, recombination and other processes (Gartenberg, 2000).

\section{Yeast}

Studies in the budding yeast, Saccharomyces cerevisiae, have been key to understanding chromatin regulation in higher organisms. This is partly due to the fact that $S$. cerevisiae is an atypical eukaryote in terms of chromatin structure. Chromatin in $S$. cerevisiae does not compact in the same way as it does in other eukaryotes; instead, it is generally found in a euchromatic, or lightly packed, conformational state that is more amenable to transcription. In fact, only three genomic locations in S. cerevisiae undergo chromatin compaction: telomeres, mating-type loci and nucleolar rDNA genes (Gartenberg, 2000). But even these heterochromatic structures are significantly different from those of higher organisms because they lack important hallmarks of chromatin compaction such as H3K9 methylation and heterochromatin-specific structural proteins (Buck et al., 2004). In fact, heterochromatin formation in $S$. cerevisiae is based mainly on histone hypoacetylation, which, although capable of producing a certain degree of compaction in the chromatin fiber, cannot do so to the extent seen in the heterochromatin of higher eukaryotes (Kurdistani et al., 2004; Robyr et al., 2002). Consequently, S. cerevisiae's particular type of chromatin makes histone deacetylases major players of chromatin organization in yeast. This is a rather surprising finding considering that, after histone deacetylation, H3K9 methylation is the most conserved feature of silenced chromatin in eukaryotes (Klose et al., 2007; Krauss, 2008; Schotta 
et al., 2002). Given that this modification is already present in members of the kingdom Amoebozoa, H3K9 methylation probably developed in the early stages of eukaryotic evolution. Comparisons with Neurospora and Schizosaccharomyces, which are close relatives of Saccharomyces that conduct H3K9 methylation, suggest that, whereas their shared ancestor probably had this activity, Saccharomyces lost it as it evolved a more compact genome (Krauss, 2008).

The establishment of heterochromatic loci in Saccharomyces depends on the activity of the first described sirtuin, ScSir2p. The four SIR genes, SIR1 to 4 , were identified as mutations that allowed the abnormal expression of the normally silent matingtype genes (Rine et al., 1979). Their gene products are involved in the epigenetic silencing of the mating-type loci through binding to the silencer regions of the HMR and HML loci, located in the different arms of chromosome three. Sir1p is responsible for establishing gene silencing via its interaction with ORC1, a component of the origin of replication complex (ORC) and transcription factors such as Rap1p and Abf-1 in the $H M R / H M L$ silencer region (Fig. 2A). The process of mating-type loci silencing involves the arrival of Sir1p, followed by the recruitment of Sir3p and the complex Sir4p-ScSir2p (Moazed et al., 1997). Both Sir3p and Sir $4 p$ bind chromatin through direct interaction with histones $\mathrm{H} 3$ and H4. The recruitment of ScSir2p (as a Sir4pScSir2p complex), results in deacetylation of $\mathrm{H} 3$ and $\mathrm{H} 4$ tails, and particularly H4K16Ac. Once loaded, the heterochromatin structure spreads via binding of Sir3p and Sir4p-ScSir2p to the adjacent hypoacetylated $\mathrm{H} 3$ and $\mathrm{H} 4$, which in turn recruits and causes further deacetylation (Fig. 2A) (Gartenberg, 2000). Moreover, H4K16 hypoacetylation is recognized as a signature of ScSir2psilenced regions (Robyr et al., 2002). Conversely, it is known that the Sir complex spreading is inhibited by $\mathrm{H} 4 \mathrm{~K} 16$ acetylation and that boundary regions in silenced heterochromatin have hyperacetylated H4K16 (Ekwall, 2005; Kimura et al., 2002; Suka et al., 2002). It has actually been shown that H4K16Ac HAT (histone acetyltransferase) Sas $2 p$ creates gradients of H4K16Ac that control ScSir2p-silencing extension (Kimura et al., 2002; Suka et al., 2002).

Although ScSir2p is involved in the silencing of telomeres, mating-type loci and nucleolar rDNA genes, the Sir proteins that act on these regions of heterochromatin are not always the same (Fig. 2 A-C). For example, whereas telomere silencing involves Sir3p and Sir4p but not Sir1p, rDNA silencing does not require any of these (Grunstein, 1997) (Fig. 2C). ScSir2p-induced telomere silencing (Fig. 2B) can extend into a chromosome anywhere from $2 \mathrm{~kb}$ to $19 \mathrm{~kb}$ and participate in position effect variegation (PEV) (Aparicio et al., 1991; Lieb et al., 2001). Sir4p is responsible for establishing the extent of ScSir2p-induced telomere silencing by binding to Rap1p and the DNA repair protein Ku70p. Upon arrival of theSir4p-ScSir2p complex, Sir3p is also recruited, initiating
Fig. 2. Model of Sir2-dependent Heterochromatin formation in $S$. cerevisiae. (A) Mating-type loci: Sir1 participates in the establishment of the heterochomatin structure during S-phase through binding to silencer-bound proteins such as ORC1p, Rap1 and Abf1p and recruitment of the rest of the SIR machinery. Different models have been proposed to describe this process but it is commonly accepted that Sir4p (present in vivo as Sir4-ScSir2p complex) is probably responsible for binding to Sir1p, which in turn is believed to bring Sir3p to chromatin, resulting in hypoacetylation of $\mathrm{H} 3$ and $\mathrm{H} 4$ as well as silencing. Once the structure is established, it can spread without Sir1p. (B) Telomeres: The SIR complex is formed in the telomeric regions, through binding to Rap1. Sir3p and Sir4p bind to Rap1p independently and recruit ScSir2p. The complex spreads similarly as in the mating-type loci. (C) Nucleolar silencing of rDNA. Each of the 100-200 repeats distributed in tandem is around $9.1 \mathrm{~kb}$ and composed of two regions: $35 S$ (blue arrows), formed by 185 and 25S, and NTS (Non transcribed spacer). The latter consists of a $5 S$ gene and two flanking regions named NTS1 and NTS2. Transcription of each repeat renders a RNA pol-I dependent $35 S$ precursor rRNA and a RNA-pol III-depen-

dent $5 S$ rRNA precursor. The RENT complex binds to two regions, NTS1 and NTS2. In both cases, RENT recruitment to chromatin requires binding to specific factors, fob $1 \mathrm{p}$ in the case of NTS1, and RNA-polymerase Ip (RNA-pol-I) in the case of NTS2. Binding of RENT to NTS2 spreads into the coding region of 18S (Huang and Moazed, 2003). Based on Huang and Moazed, 2003.
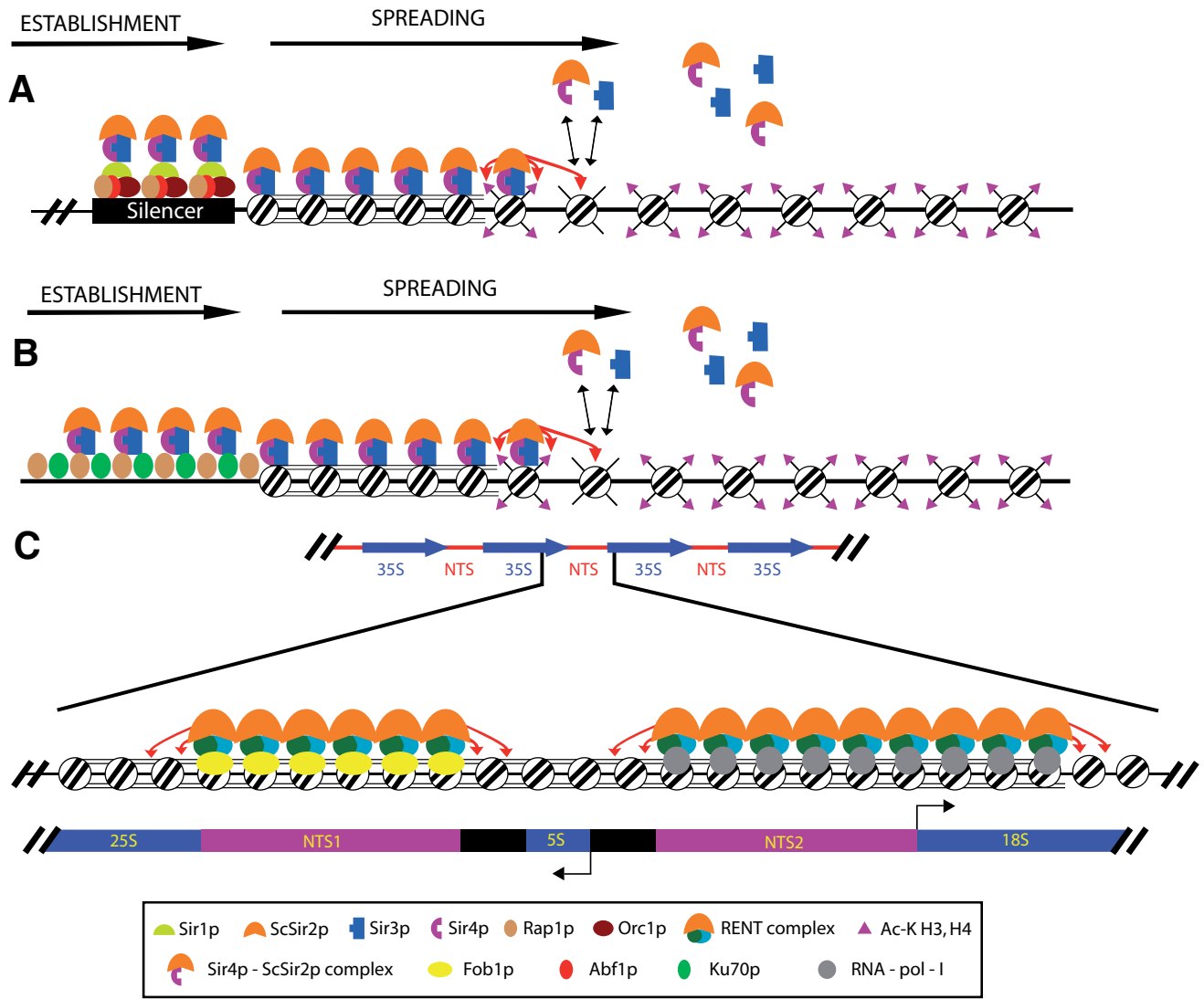
heterochromatic spreading through a mechanism very similar to the mating-type loci (Fig. 2B). Interestingly, ScSir2p and Sir3p have been found to relocalize from telomeres to non-homologous end-joining (NHEJ) DNA repair sites in double-strand break (DSB) events, suggesting that they have a role in these processes (Mills et al., 1999). However, it is unknown whether these sirtuins directly participate in DNA repair.

The third example of heterochromatin in $S$. cerevisiae, the rDNA loci, is located on chromosome 12 and comprises 100 to 200 tandem copies of rDNA genes. In this locus, ScSir2p induces epigenetic silencing in the context of a complex called RENT (regulator of nucleolar silencing and telophase exit), where it associates with Net1p and the phosphatase Cdc14p. Net1p interacts directly with ScSir2p and is responsible for keeping ScSir2p in the nucleolus (Fig. 2C) (Straight et al., 1999). It binds to DNA polymerase I (Pol I) and seems to be directly involved in regulating the nucleolus structure (Shou et al., 2001). In contrast, Cdc14p is involved in mitosis control, particularly during anaphase exit (Hogan and Koshland, 1992). In non-mitotic stages, Cdc14p is sequestered in the nucleolus by the RENT complex and released in early anaphase by phosphorylation (Shou et al., 1999). Interestingly, ScSir2p is also linked to meiosis in two ways: firstly, through Cdc14p, which is also involved in meiosis-l exit and control of the sequential meiotic program (Marston et al., 2003); and secondly, as revealed by genetic studies, through the meiosis checkpoint protein Pch2p, with which it is involved in meiotic regulation-specifically, in the pachytene phase of meiosis I (San-Segundo and Roeder, 1999). Pch2p is tethered to the nucleolus through a ScSir2p-dependent mechanism, but whether this effect is due to direct interaction between the two factors is unknown.

An outcome of ScSir2p nucleolar silencing is its inhibitory effect on recombination events that occur within rDNA genes. This has linked ScSir2p to the replicative lifespan increase observed in yeast, since rDNA recombination produces extrachromosomal rDNA circles (ERC) whose accumulation is toxic and seems to be associated with ageing in this organism (Gottlieb and Esposito, 1989; Sinclair et al., 1998).

In addition to SIR2, S. cerevisiae contains four other sirtuins, named HST (homologs of Sir-two) 1 through 4. Interestingly, all of these are Class I sirtuins, like ScSir2p, suggesting that their functions might be related to chromatin and may include histone deacetylase activity (Fig. 1).

Hst1p is the closest homolog of ScSir2p and is product of a relatively recent gene duplication event, since close relatives of $S$. cerevisiae such as Kluyveromyces lactis or S. pombe only contain one gene (Hickman and Rusche, 2007). Hst1p is located in the nucleus like ScSir2p and is involved in silencing middle sporulation genes. Hst1p gets recruited to its target genes by the transcription factor Sum $1 p$ and induces repression by deacetylating $\mathrm{H} 3$ and $\mathrm{H} 4$ tails (Xie et al., 1999). Hst1p also participates in the regulation of some genes of the kynureine pathway, which is involved in the de novo formation of $\mathrm{NAD}^{+}$(Bedalov et al., 2003; Robert et al., 2004). Interestingly, Sum1p is actually responsible for recruiting Hst $1 p$ to virtually all its target genes; indeed, deletion of SUM1 impairs Hst1p localization in ChIP-on-chip experiments. Additionally, Hst1p has been found in SET3C, a complex which participates in meiotic repression and sporulation together with other factors, among which is the HDAC Hos 2 p (Pijnappel et al.,
2001). However, given the ChIP-on-chip results described above, and the fact that Hst1p is not responsible for the activity of the complex, the implications of this finding are unknown.

Studies have shown that Hst1p function can rescue some of the silencing defects in SIR2A strains, whereas ScSir2p still retains the capacity of interacting with Sum1p and rescues most of HST1 1 defects in sporulation (Hickman and Rusche, 2007). This finding suggests that the capacity to bind to Sum1p existed in the original SIR2/HST1 encoded protein, whereas the SIRmediated heterochromatin developed after the duplication event. This conclusion is supported by the lack of the rest of SIR proteins outside of $S$. cerevisiae.

Hst2p is located in the cytoplasm, although it seems to be present in the nucleus in small levels. This is caused by an active nuclear export mechanism that has been recently described (Wilson et al., 2006). Hst2p overexpression is known to be able to affect ScSir2p silencing: it increases rDNA repression while derepressing ScSir2p-dependent telomeric silencing (Perrod et al., 2001). These genetic observations might be explained by recent evidence suggesting that $\mathrm{Hst} 2 \mathrm{p}$ is involved in nuclear epigenetic silencing in certain cases. Hst2p and Hst $1 \mathrm{p}$ participate in silencing of the subtelomeric flocculation gene FLO10, which encodes a cell-wall glycoprotein, important for cell-surface and cell-cell adhesion (Halme et al., 2004). Moreover, ChIP-on-chip studies in S. pombe have shown that SpHst2, the Hst2p homolog, is involved in rDNA and centromeric silencing, as well as in gene repression of a specific subset of genes (Durand-Dubief et al., 2007). However, the exact role for Hst2p in both cases is currently unknown.

Like its mammalian homolog SirT2, Hst2p has histone deacetylase activity specific for H4K16Ac and, to a lesser extent, H3K9Ac (Vaquero et al., 2006). In contrast to ScSir2p or Hst1p, loss of Hst2p in yeast produces global hyperacetylation of H4K16Ac. These observations might suggest a role for Hst2p in control of global cell cycle-dependent H4K16Ac levels. This hypothesis is reinforced by the fact that SirT2 has been shown to localize to chromatin during the $\mathrm{G}_{2} / \mathrm{M}$ transition and deacetylate H4K16Ac prior to cell cycle entry into mitosis (Vaquero et al., 2006). However, it is not known whether Hst2p in yeast is responsible for the drop in $\mathrm{H} 4 \mathrm{~K} 16 \mathrm{Ac}$ prior to mitosis analogously to SirT2 in mammals. Another facet of Hst2p function that remains unknown is its reported involvement in lifespan increase through an uncharacterized ScSir2p-independent pathway (Lamming et al., 2005).

Hst3p and Hst4p are involved in the deacetylation of H3K56Ac, a residue present in the globular domain of histone $\mathrm{H} 3$, which occurs outside of S-phase (Celic et al., 2006; Maas et al., 2006). Global levels of H3K56Ac depend on S-phase progression and seem to be associated with a transient stage of histone $\mathrm{H} 3$ deposition. This modification is part of the replication-dependent DNA damage response mediated by the Mec1p-dependent pathway. In fact, Hst3p and Hst4p are cell-cycle regulated and are responsible for keeping $\mathrm{H} 3 \mathrm{~K} 56 \mathrm{Ac}$ levels low through cell cycle except during replication (Celic et al., 2006; Maas et al., 2006). However, upon DNA damage, their expression is downregulated, rendering $\mathrm{H} 356 \mathrm{Ac}$ hyperacetylation, a mechanism that seems to be key for DNA damage response and survival under these conditions (Masumoto et al., 2005). Additionally, recent studies suggest that ScSir2p itself can deacetylate H3K56Ac, and in 
doing so, somehow enforces heterochromatin formation (Xu et al., 2007).

Chromatin organization and regulation in the fission yeast Schizosaccharomyces pombe is very different from that of $S$. cerevisiae. Firstly, the chromatin in S. pombe is organized much more similarly to that of higher eukaryotes. Specifically, it conducts H3K9 methylation and has a heterochromatin specific protein, Swi6p, which is a homolog of metazoan HP1 (Grewal and Jia, 2007). Unlike S. cerevisiae, which encodes five sirtuins (ScSir2p, Hst1p to Hst4p), S. pombe only has three (SpSir2, SpHst2 and SpHst4) (Fig. 1) (Freeman-Cook et al., 2005). SpSir2, like ScSir2p, is not essential for viability and localizes to the nucleus. ChIP-on-chip assays show that SpSir2 is involved in silencing heterochromatin in telomeres, mating-type loci, and centromeres, but apparently not in nucleolar rDNA (FreemanCook et al., 2005). The model of SpSir2-mediated heterochromatin implies deacetylation of $\mathrm{H} 3$ and $\mathrm{H} 4$, particularly $\mathrm{H} 3 \mathrm{~K} 9 \mathrm{Ac}$ and H4K16Ac, methylation of H3K9 and Swi6p recruitment to these regions (Freeman-Cook et al., 2005; Shankaranarayana et al., 2003). However, at least in centromeric heterochromatin, the main target of SpSir2p is H3K9Ac and not H4K16Ac (Mellone et al., 2003). Thus, deacetylation of H3K9Ac by SpSir2p is required for trimethylation of $\mathrm{H} 3 \mathrm{~K} 9$ by $\mathrm{Clr} 4$, and the subsequent arrival of Swi6 (Shankaranarayana et al., 2003).

$\mathrm{SpHst2}$ protein is cytoplasmic, but resides in low amounts in certain heterochromatic regions of the nucleus with the remaining sirtuins (Durand-Dubief et al., 2007). Meanwhile, SpHst4 is cell cycle regulated like Hst4p and is probably involved in H3K56Ac control (Haldar and Kamakaka, 2008), although in some conditions it has been reported to localize with SpSir2 and SpHst2. Notably, all three $S$. pombesirtuins are involved in retrotransposon silencing, but their exact role in this context is unknown (DurandDubief et al., 2007).

\section{Protozoa}

Knowledge of sirtuin function in unicellular eukaryotes has also benefited from studies of the parasitic protozoa that cause human diseases such as malaria, Chagas' disease, sleeping sickness and leishmaniasis. The studies have focused on three genera; Plasmodium, Trypanosoma and its close relative Leishmania.

Among the different species of the Plasmodium genus, Plasmodium falciparum is responsible for the most severe form of malaria. A major factor that determines the virulence of the infection is a group of Plasmodium falciparum genes that encode cell surface proteins. These proteins are expressed by infected erythrocytes during the blood stage of the parasite's infective life cycle and are recognized by the host's immune system (Merrick and Duraisingh, 2006). Much of the parasite's success is due to mechanisms it has developed to avoid immune system recognition. One such mechanism known as antigenic variation, which is used by Plasmodium and other parasites, is based on switching the expression of these surface proteins so that only one of their genes is expressed at a time (Scherf et al., 1998). Most important among the antigenic proteins are the adhesins encoded by the var gene family. Plasmodium contains around 60 var genes, which are mainly distributed in clusters along subtelomeric regions, although some copies exist around the center of chromosomes. The var genes are controlled by three types of promoters: upsA, $B$ and $C$. Ups $A$ and $B$ are located mainly in telomeric regions, whereas UpC are located in more central position of the chromosomes (Merrick and Duraisingh, 2006).

Contrary to Trypanosoma, var gene antigenic variation in Plasmodium is not based on recombination events, but rather on epigenetic silencing of inactive genes, which greatly depends on the sirtuin PfSir2(Duraisingh et al., 2005; Freitas-Junior et al., 2005). Although $P$. falciparum contains two sirtuins, only PfSir2 has been characterized. PfSir2 shows both histone deacetylase and ADP-ribosyltransferase activities (Merrick and Duraisingh, 2007). It is predominantly located in subtelomeric regions and in the nucleolus. Interestingly, yeast ScSir2p also localize to these two loci, suggesting a conserved sirtuin role in both locations.

Disruption of PfSir2 function leads to deregulation of many inactive subtelomeric var genes, especially those regulated by ups $A$ and, to a lesser extent, by upsB (Gardner et al., 2002). Chromatin immunoprecipitation (ChIP) experiments have shown that var gene activation is associated with histone $\mathrm{H} 4$ hyperacetylation in its promoter and $5^{\prime}$ coding regions as well as loss of PfSir2 from these regions (Duraisingh et al., 2005). These finding suggest that, as with sirtuins in budding yeast, those in $P$. falciparum are involved in generating heterochromatin-like structures in subtelomeric regions via deacetylation of histone $\mathrm{H} 4$ and possibly, H3.

Although not completely understood, the role of Sir2 in telomeric var gene silencing might resemble, in some aspects, to $S$. cerevisiae mating-type loci. However in this case, contrary to ScSir2p, the PfSir2-dependent silencing also involves methylation of H3K9. This is supported by studies demonstrating that var gene silencing correlates with a loss of acetylation in histone $\mathrm{H} 3$ lysine 9 and with trimethylation of lysine 9 throughout the gene (Lopez-Rubio et al., 2007). However, whether PfSir2 is directly responsible for histone $\mathrm{H} 3$ lysine 9 acetylation and $\mathrm{H} 3 \mathrm{~K} 9 \mathrm{me} 3$ methyltransferase recruitment, and the reason why loss of PfSir2 affects certain promoter-controlled var genes, remain unknown. Additionally, the roles of PfSir2 in the nucleolus, and whether the other uncharacterized P.falciparum sirtuin plays a role in the organism's pathogenicity, have yet to be determined. Such studies could reveal a way to inhibit antigenic selection of $P$. falciparum by directly targeting its Sir2 family members. The fact that PfSir2 is sensitive to nicotinamide in vitro but is not affected by other drugs that modulate eukaryotic sirtuins, suggests that drugs capable of exclusively inhibiting this parasite's sirtuin activity without affecting that of the host could be developed (Merrick and Duraisingh, 2007).

Other well characterized protozoan sirtuins belong to the flagellate Tripanosoma brucei, which is responsible for African sleeping sickness. T. brucei contains three sirtuins: two Type I members, TbSIR2RP1 and TbSIR2RP3, and a Type II member, TbSIR2RP2, related to bacterial sirtuins (Garcia-Salcedo et al., 2003). Like Plasmodium PfSir2, TbSIR2RP1 is nuclear and shows in vitro both deacetylase and ADP-ribosyltransferase activity of histones, and in particular $\mathrm{H} 2 \mathrm{~A}$ and $\mathrm{H} 2 \mathrm{~B}$, and is located in subtelomeric regions where it participates in heterochromatin formation (Garcia-Salcedo et al., 2003). However, TbSIR2RP1 is not involved in antigenic variation. Additionally, although loss of TbSIR2RP1 does not result in lethality under normal conditions, it renders $T$. brucei hypersensitive to DNA-damaging drugs such as methanesulfonic acid methyl ester (MMS), suggesting that TbSIR2RP1 may also be implicated in DNA repair (Alsford et al., 
2007).

In contrast to Trypanosoma, its close relative Leishmania does not appear to have nuclear sirtuins. Its only sirtuin studied to date, LmSIR2, is localized to the cytosol (Vergnes et al., 2002). The other sirtuin appears to be related to bacterial sirtuins and therefore is likely located in the mitochondria (Frye, 2000). LmSIR2 has not yet been characterized enzymatically, but it is known to be indispensable to the parasite's survival, making it one of the few described essential sirtuins. The only role attributed to $L m S I R 2$ is the promotion of survival under stressful conditions during certain stages of the parasite's life cycle (Vergnes et al., 2002; Vergnes et al., 2005). However, the mechanism through which LmSIR2 accomplishes this is completely unknown, although chromatin regulation is a possibility. In fact, $L m S I R 2$ belongs to the Type I sirtuins, whose members are generally chromatin related. There is already a precedent for this in humans, in which the cytoplasmic sirtuin SirT2 modulate H4K16Ac levels throughout the cell cycle (Vaquero et al., 2006).

\section{C. elegans and Drosophila}

As in previous stages of chromatin evolution, sirtuins adapted to new functions that arose with multicellular eukaryotes, cellular differentiation and development. One obvious adaptation is an increase in the number of sirtuins compared to that of lower eukaryotes, with the exception of $S$. cerevisiae.

Evidence suggests that sirtuins are involved in development and cell identity in both Drosophila and C. elegans. The $C$. elegans genome contains four sirtuins, denoted as Sir-2.1 to 2.4. (Fig. 1). Current knowledge on these is limited to a few studies and functional comparisons with better-known mammalian counterparts. Presently, there is no biochemical evidence to support any enzymatic activity for the nematode sirtuins.

Sir-2.1 is Type I sirtuin and the sirtuin most closely related to ScSir2p. The fact that Sir-2.1 has a nuclear localization and is phylogenetically close to mammalian SirT1 (Frye, 2000) suggests that it is probably a histone deacetylase and might have a role in chromatin regulation. This idea is reinforced by the fact that Sir2.1 participates in the silencing of repetitive transgenes in C.elegans (Jedrusik and Schulze, 2003) and is involved in germline silencing (Jedrusik and Schulze, 2007). Nevertheless, most studies of Sir-2.1 have focused on whether extra copies of this gene promote lifespan increase (Tissenbaum and Guarente, 2001). Said effect has been observed under conditions of stress when Sir-2.1 interacts with the insulin-like signaling pathway via the forkhead transcription factor DAF-16 and the chaperone protein 14-3-3 (Berdichevsky et al., 2006). Although loss-offunction mutations in the insulin-like receptor DAF-2 are known to negate the lifespan-increasing ability of Sir-2.1 (Tissenbaum and Guarente, 2001), the mechanism by which Sir-2.1 extends lifespan is unidentified. Since mammalian sirtuins can deacetylate FOXO forkhead factors and modulate their transcriptional activities (Giannakou and Partridge, 2004), the same could occur in C. elegans. Interestingly, Sir-2.1 has been linked to survival phenomena in other studies. For instance, it has been found to protect against polyglutamine-induced neuronal dysfunction (Bates et al., 2006) and to regulate levels of key mediators of the endoplasmic reticulum (ER) unfolded-protein response (Viswanathan et al., 2005).
Sir-2.2 and Sir-2.3 are Type II sirtuins, and like mammalian SirT4, share homology with some mitochondrial proteins. However, considering that Sir-2.2 has been found in a genome-wide RNAi screen for promoters of genome stability together with other chromatin-related factors (e.g. HDACs 1 to 4, lysine methyltransferases, the HDAC-related factor Sin3, and many DNA repair proteins) (Pothof et al., 2003), it may be localized to the nucleus, where it could directly regulate chromatin functions. In fact, although not involved in lifespan increase, Sir-2.2 seems to share Sir-2.1's ability to protect $C$. elegansfrom neurodegeneration whereas no effect has been observed with Sir-2.3 (Bates et al., 2006).

Sir-2.4, like mammalian SirT6 and SirT7, is a Type IV sirtuin, and like Sir-2.2, is not involved in lifespan increase. However, beyond this, their function is completely unknown.

Drosophila melanogaster contains five sirtuins, which, due to their homology with mammalian sirtuins, are named DmSir2 (or DmSirT1), DmSirT2, DmSirT6 and DmSirT7.

The only one of them studied so far is DmSir2, the ortholog of C. elegans Sir-2.1.

Like ScSir2p and Sir-2.1, DmSir2 promotes lifespan increase through a mechanism that involves caloric restriction (Rogina et al., 2002). DmSir2 is clearly involved in chromatin functions, particularly those related to development. Although $D m S i r 2$ is involved in PEV (Position effect variegation) (Newman et al., 2002; Rosenberg and Parkhurst, 2002) - suggesting that it is required for heterochromatin-mediated silencing-and despite its shared conservation with sirtuins in lower eukaryotes, it does not seem to regulate telomere heterochromatin (Rosenberg and Parkhurst, 2002). Rosenberg and Parkhurst reported some controversial genetic and biochemical data suggesting that $D m S i r 2$ interacts with the transcriptional repressors Hairy and Deadpan, which are members of the HES (Hairy Deadpan Enhancer of $\underline{S}$ plit) family (Rosenberg and Parkhurst, 2002). The HES family of transcription factors contains a bHLH (basic helix-loop-helix) domain, and plays a key role in developmental processes through transcriptional repression of certain key genes (Younger-Shepherd et al., 1992). Hairy and Deadpan recruit repressors, such as the histone deacetylases $D m R p d 3$ and maybe $D m S i r 2$, to their target genes. (Bianchi-Frias et al., 2004). However, this data is currently being challenged (Astrom et al., 2003).

Another finding that suggests a role for DmSir2 in developmental processes is the identification of DmSir2 as part of a Polycomb complex, which contains factor $E(Z)$ (Enhancer of zeste), a histone methyltransferase involved in long-range epigenetic silencing of the spatially-restricted expression pattern exhibited by homeotic genes during Drosophila development (Furuyama et al., 2004). Epigenetic silencing by Polycomb factors is based on the trimethylation of $\mathrm{H} 3 \mathrm{~K} 27$ and resembles in some aspects ScSir2p-dependent silencing of heterochromatin. DmSir2's involvement in development seems to be very dynamic (Furuyama et al., 2004; Newman et al., 2002; Rosenberg and Parkhurst, 2002). For example, DmSir2 mRNA levels peak at early stages of embryogenesis, then decrease progressively until stabilizing in adults. Furthermore, localization of $D m S$ ir2 can change from the nucleus to the cytoplasm or encompass both locations simultaneously during different stages of the differentiation program (Rosenberg and Parkhurst, 2002). However, DmSir2 loss-offunction mutants are viable, suggesting a strong redundancy 
among the Drosophila sirtuins (Astrom et al., 2003; Newman et al., 2002). Further studies are needed to clarify the role of other Drosophila sirtuins and determine the existence of a common function in development.

\section{Mammalian sirtuins}

Knowledge of sirtuin function has recently surged. This has partly been the result of characterization of mammalian sirtuins and their functional implications in lifespan regulation, cancer, neurological diseases (e.g. Alzheimer's and Parkinson's), and hormone-related pathologies.

Due to the lack of information on $C$. elegans and Drosophila sirtuins, current views on the adaptative course of sirtuins in throughout the evolution of higher eukaryotes are based almost exclusively on mammalian sirtuins. All evidence suggests that sirtuins adapted to increasing complexity by acquiring new functions through the targeting of a wide range of substrates (Fig. 3).

Thus, the seven mammalian sirtuins (SirT1 through 7) are a clear example of evolutionary diversification. In terms of function, SirT1 through 3 show deacetylase activity in vivo, whereas SirT4 and SirT6 exhibit specific and strong mono ADP ribosyl-transferase activity, and the main catalytic activities of SirT5 and SirT7 are currently unknown (Saunders and Verdin, 2007; Vaquero et al., 2007b). SirT1, 2, 3 and 6 preferentially target histones, specifically H4K16Ac and/or H3K9A (Vaquero et al., 2004). However, SirT1 through 3 also target non-histone proteins, including various nuclear factors (SirT1), tubulin (SirT2) and mitochondrial targets (SirT3) (Saunders and Verdin, 2007; Vaquero et al., 2007b).

Mammalian sirtuins offer a prime example of the diversity and complexity of sirtuin cellular localization patterns. SirT1, SirT6 and a small fraction of SirT3 and SirT2 are present in the nucleus, SirT2 is cytoplasmic, SirT3 through 5 are mitochondrial, and SirT7 is nucleolar (Michishita et al., 2005). Furthermore, these localizations can be dictated by cellular identity, developmental stage, environmental stimuli or cell cycle progression (Saunders and Verdin, 2007; Vaquero et al., 2007b, Yamamoto et al., 2007). For example, the localization of SirT1 varies with cell type, developmental stage and stress conditions.

\section{SirT1}

SirT1 and yeast ScSir2p are the best known of all sirtuins. In fact, SirT1 is the phylogenetic and functional ortholog of both yeast ScSir2p and Hst1p and shows the broadest range of functions as well as the widest array of substrates among sirtuins (Yamamoto et al., 2007). Said functions can be classified into four groups: chromatin organization; metabolic regulation; cell survival in stress conditions; and cell differentiation and development (see below and Fig. 3).

Although a nuclear protein, the localization of SirT1 varies with cell type and stage of differen- tiation; it can be exclusively cytoplasmic or present throughout the cell (Chen et al., 2006; Moynihan et al., 2005).

Loss of SirT1 results in prenatal or perinatal death in half of individuals; the remaining half suffer defects in gametogenesis and sterility, eyelid opening problems, chronic lung infection and pancreatic atrophy (McBurney et al., 2003a). SirT1 is expressed in all organs, but is most prevalent in the most energy dependent tissues (Michishita et al., 2005).

\section{SirT1 and chromatin regulation}

SirT1 has strong histone deacetylase activity in vitro, especially toward $\mathrm{H} 4 \mathrm{~K} 16 \mathrm{Ac}$ and $\mathrm{H} 3 \mathrm{~K} 9 \mathrm{Ac}$. RNAi studies have revealed that loss of SirT1 correlates with a global increase in H4K16Ac and $\mathrm{H} 3 \mathrm{~K} 9 \mathrm{Ac}$ together with a loss of heterochromatin marks such as $\mathrm{H} 3 \mathrm{~K} 9$ me 3 and H4K20me1, suggesting that SirT1 is involved in the formation of heterochromatin (Vaquero et al., 2004). Heterochromatin is divided into two main forms according to their distinct structural functional dynamics: constitutive heterochromatin $(\mathrm{CH})$ and facultative heterochromatin (FH) (Trojer and Reinberg, 2007). $\mathrm{CH}$ refers to the regions that are always maintained as heterochromatin, span large portions of the chromosome, and have a rather structural role. These regions contain few genes and are located primarily in pericentromeric regions and telomeres. In contrast, $\mathrm{FH}$ refers to those regions that can be formed as heterochromatin in certain situations (e.g. certain stages of the developmental program, and the cell cycle) but can revert to euchromatin once required. Facultative heterochromatin can span from a few kilobases to a whole chromosome and generally includes regions with a high density of genes (Craig, 2005; Trojer

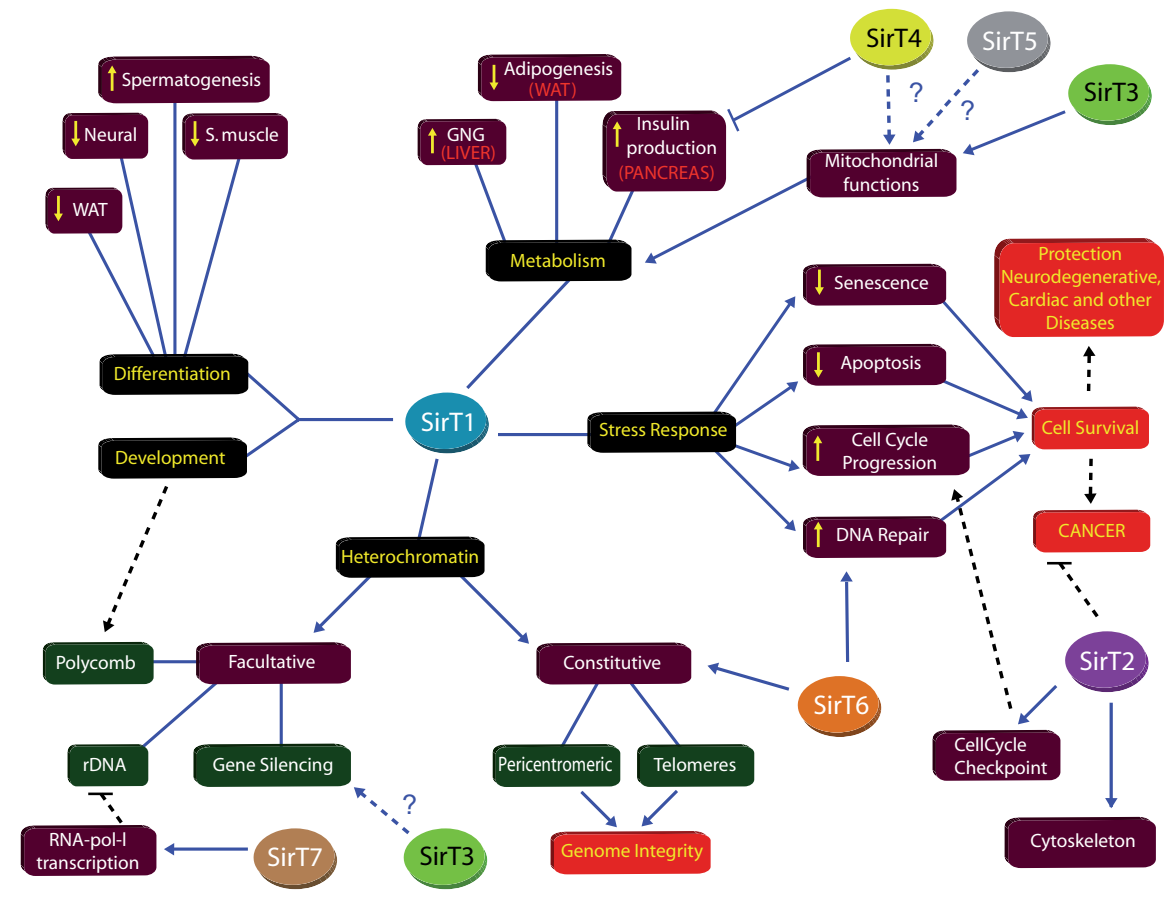

Fig. 3. Function of mammalian sirtuins. The main functions of SirT1 are indicated in black boxes. They are mediated through promotion of the indicated actions (maroon and green boxes) and consequences (red boxes). The functions of the remaining sirtuins are also listed. A question mark is used to indicate functions which have not been demonstrated. Polycomb, Ezh2 (Polycomb)-dependent silencing; WAT, white adipose tissue. 


\section{A. Vaquero et al.}

and Reinberg, 2007).

Current evidence suggests that SirT1 is actually involved in both forms of heterochromatin. Among the most important and distinctive features of SirT1 is that, in contrast to other Class I and II HDACs, it is more than just a histone deacetylase: due to its remarkable capacity to bind to many factors and target many substrates, SirT1 is actually a coordinator of heterochromatin formation (Vaquero et al., 2004; Vaquero et al., 2007b) (Fig. 4).

The main biological form of SirT1 is an homotrimer complex of ca. $350 \mathrm{kDa}$ (Vaquero et al., 2004). One other biochemically stable SirT1containing complex, PRC4, has been described (Kuzmichev et al., 2005). Like other sirtuins, SirT1 lacks the ability to directly bind DNA and must be recruited to the target DNA regions. Although numerous SirT1-targeted genes are unidentified, all data suggest that SirT1 participates in the regulation of many genes via formation of $\mathrm{FH}$ by coordinating several events (Fig. 4) (Vaquero et al., 2004).

The first event, arrival of SirT1 to chromatin, results in deacetylation of $\mathrm{H} 4 \mathrm{~K} 16 \mathrm{Ac}$ and $\mathrm{H} 3 \mathrm{~K} 9 \mathrm{Ac}$, and direct recruitment of the linker histone $\mathrm{H} 1$, a key factor in the formation of the $30 \mathrm{~nm}$ fiber (Hansen, 2002). In fact, SirT1 seems to interact specifically with one of the five somatic variants, $\mathrm{H} 1 \mathrm{~b}$ (also known as $\mathrm{H} 1.4$ ), which is particularly enriched in heterochromatin and assembled into chromatin during late S-phase (D'Incalci et al., 1986; Parseghian et al., 2001; Parseghian et al., 2000). SirT1 not only interacts and recruits histone $\mathrm{H} 1$, it can also deacetylate histone $\mathrm{H} 1$ at lysine $\mathrm{K} 26$ in vitro and in vivo (Vaquero et al., 2004). There are findings that suggest a role for $\mathrm{H} 1 \mathrm{~K} 26$ deacetylation in heterochromatin formation, although this has yet to be demonstrated. Firstly, acetylation of $\mathrm{H} 1 \mathrm{~N}$-terminal domain could act similarly as in the core histones, weakening intra- and internucleosomal interactions and thus favoring a less compacted chromatin structure (Vaquero et al., 2004). Secondly, H1K26 is methylated by the Polycomb protein Ezh2, homolog of Drosophila $\mathrm{E}(\mathrm{Z})$ (Kuzmichev et al., 2004). Since in mammals, as in Drosophila, SirT1 coexists with Ezh2 in the PRC4 complex, deacetylation of $\mathrm{H} 1 \mathrm{~K} 26 \mathrm{Ac}$ by SirT1 could allow coordinated methylation by Ezh2. Thirdly, HP1 proteins bind to dimethylated H1bK26 through its chromodomain, an interaction inhibited by phosphorylation of the adjacent serine 27 (Daujat et al., 2005; Nielsen et al., 2001a). This mechanism might explain the targeting of HP1 to certain regions in the absence of $\mathrm{H} 3 \mathrm{~K} 9$ methylation in Xenopus (Meehan et al., 2003). Finally, $\mathrm{H} 1 \mathrm{~b}$ is also present in a complex formed by L3MBTL1, core histones, HP1 $\gamma$ and retinoblastoma $(\mathrm{Rb})$. The MBT (malignant brain tumor) factor L3MBTL1 promotes heterochromatin formation through binding to mono- and di- methylated H4K20 and H1K26me3 (Trojer et al., 2007).

Upon arrival of SirT1, loss of the active chromatin mark H3K79me2 is observed (Fig. 4). Loss of this mark-which is involved in transcriptional active chromatin, DNA damage response and meiotic checkpoint control and is located in the globular domain of histone H3 (Feng et al., 2002; Kouskouti and Talianidis, 2005) — spreads a few kilobases away from the promoter regions. Interestingly, this modification is very important for establishing the boundaries of ScSir2p silencing in S. cerevisiae, since it inhibits the spread of the ScSir2p/3p/4p complex and is absent in Sir2-silenced regions ( $\mathrm{Ng}$ et al., 2002). Nevertheless, the mechanism behind that loss is not understood. Whether SirT1 is directly involved, or if the mechanism requires histone exchange activity or a demethylase activity, should be addressed in future studies.

Lastly, SirT1 arrival promotes the establishment of heterochromatin marks, particularly H3K9me3 and H4K20me1, which spread throughout the coding region of the gene (Vaquero et al., 2004). The mechanism involved in the establishment of these marks is known for H3K9me3, but not for H4K2Ome1. SirT1 promotes the establishment of $\mathrm{H} 3 \mathrm{~K} 9 \mathrm{me} 3$ through an intimate functional relationship with Suv39h1, the main enzyme responsible for the modification (Vaquero et al., 2007a). Suv39h1 was the first lysine methyltransferase ever described (Rea et al., 2000)and is a key player in chromatin organization, through maintenance of $\mathrm{H} 3 \mathrm{~K} 9 \mathrm{me} 3$ levels in both pericentromeric and telomeric $\mathrm{CH}$ (Peters et al., 2001). It is also involved in formation of $\mathrm{FH}$ in certain regions (Nielsen et al., 2001b). The importance of this activity is reflected by several pieces of evidence. Firstly, loss of both Suv39h1 and its close relative Suv39h2 (Suv39DN) during murine development leads to a complete loss of H3K9me3 in the pericentromeric heterochromatin as well as to a substantial re- 
duction in H3K9me3 levels in telomeres (Peters et al., 2001). This produces a loss of heterochromatin, demonstrated by loss of HP1 proteins and relocalization of $\mathrm{H} 4 \mathrm{~K} 16 \mathrm{Ac}$ to the heterochromatic foci (Vaquero et al., 2007a), chromatin segregation problems, delay in the $G_{2}$ to $M$ transition, and DNA damage. Interestingly, loss of either of these does not affect H3K9me3 levels, suggesting the importance of maintaining the levels of the modification through the developmental program (Peters et al., 2001). Moreover, in adult tissues Suv39h1 is ubiquitously expressed, whereas Suv39h2 is restricted to the testes, where it seems to be involved in heterochromatic regulation during meiosis (O'Carroll et al., 2000). The functional relationship between SirT1 and Suv39h1 challenges current views on the interplay between histone deacetylases and methyltransferases and suggests a more intimate association between these groups of enzymes than previously understood. In fact, evidence in $S$. pombe suggest that this relationship is conserved from yeast to humans (Shankaranarayana et al., 2003).

SirT1 promotes Suv39h1-dependent H3K9me3 methylation through four different mechanisms (Vaquero et al., 2007a). Firstly, SirT1 directly recruits Suv39h1 to regulatory regions through its $\mathrm{N}$-terminal region (SirT1-Nt), the same one involved in $\mathrm{H} 1$ recruitment (Vaquero et al., 2004). In the case of Suv39h1, the domain involved in the interaction involves the first 88 residues, which include the chromodomain (residues 44 to 88 ), involved in binding to $\mathrm{HP1}$, and an N-terminal region (residues 1 to 43) with an unknown function. Interestingly, the chromodomain alone retains the capacity of SirT1 binding, which suggests that SirT1 might compete with HP1 for the binding to Suv39h1. Secondly, SirT1 deacetylates $\mathrm{H} 3 \mathrm{~K} 9 \mathrm{Ac}$ to allow methylation of the same residue by Suv39h1 in the regulatory regions. Thirdly, SirT1-Nt specific binding to Suv39h1 increases its methyltransferase activity in vitro and in vivo, probably through a conformational change. As with $\mathrm{H} 1$, this binding capacity is specific for SirT1, given that overexpression of the SirT1 N-t domain, a domain specific to SirT1, results in a global increase in H3K9me3 (Vaquero et al., 2007a). Finally, SirT1 deacetylates K266 of Suv39h1, a residue located in the catalytic SET domain, rendering the enzyme more active. K266 is conserved through evolution in all high eukaryotic Suv39h1 orthologs and a remarkable number of SET-containing methyltransferases. Although the role of K266 in heterochromatin formation, and its implications for Suv39h1 functions, remain unknown, comparative studies with the crystal structure of $S$. pombe Clr4 strongly suggest that this residue is located in an exposed loop important for proper folding of the SET domain (Min et al., 2002). This would explain how acetylation and deacetylation can modulate the enzymatic activity of Suv39h1.

Although this is the only known case of acetylation/deacetylation of a methyltransferase to date, the degree of conservation in the SET-containing family of HMTs-which includes almost all lysine methyltransferases-suggests that this mechanism may be more general. One obvious case is Ezh2, the H3K27me3 and H1K26me2/3 methyltransferase that has conserved K266 from Drosophila to humans (Vaquero et al., 2007a). It is possible that in the context of PRC4, SirT1 might modulate Ezh2 activity, not only via histone deacetylation, but also through a direct effect on the SET domain of Ezh2. Further studies are required to determine the extent of this modification.

An intriguing and unexplained aspect of the relationship of
SirT1 to Suv39h1 and to Ezh2 in heterochromatin formation is the role of these in DNA methylation. Both Suv39h1 and Ezh2 have been found to bind directly to Dnmt1 - and also to Dnmt3a in the case of the former-and direct DNA methylation to specific genes (Fuks et al., 2003; Vire et al., 2006). SirT1 has also been found to interact with Dnmt1 in nucleolar rDNA. However, the SirT1 knockdown does not affect DNA methylation levels, whereas loss of Dnmt1 leads to hyperacetylation of H4K16Ac and H3K9Ac (Espada et al., 2007).

All current evidence suggests that in the genes or affected regions, proper DNA methylation requires the presence of certain methyltransferases (e.g. Suv39h1, Ezh2 and G9a). In contrast, SirT1 heterochromatin-induced silencing is a phenomena that occurs downstream of the DNA methylation. In agreement with this, loss of SirT1 leads to a loss of silencing in certain tumor suppressor genes, although it does not alter DNA methylation levels (Pruitt et al., 2006). A possible explanation for this is that different Suv39h1 complexes are involved in both stages: DNA methylation establishment and heterochromatin formation. This premise is supported by several lines of evidence: first, Suv39h1 interacts with many chromatin and transcription factors, including HDAC1, 2 and 3, and is part of the Rb-repressing complex (Vaute et al., 2002); second, SirT1 was recently found to interact with Suv39h1 and the H3K9me binding protein Nuclomethylin in rDNA loci and induce silencing of these genes in conditions of energetic stress (Murayama et al., 2008).

The relevance of the relationship between SirT1 and Suv39h1 actually goes beyond $\mathrm{FH}$; as in the case of $S$. pombe, it also affects $\mathrm{CH}$, which supports a general role for SirT1 in the global organization of mammalian chromatin (Vaquero et al., 2007a). Mouse embryonic fibroblasts (MEFs) derived from SirT1\%- knockout mice show a complete loss of $\mathrm{H} 3 \mathrm{~K} 9 \mathrm{me} 3$ levels in the $\mathrm{CH}$ foci in approximately $50 \%$ of their cells, which correlates with mislocalization of HP1 $\alpha$ in the same foci. Transfection of SirT1 in these cells produces a full recovery of $\mathrm{H} 3 \mathrm{~K} 9 \mathrm{me} 3$ levels, demonstrating direct involvement of SirT1 in this phenotype. Interestingly, and in agreement with biochemical data, this recovery requires both the $\mathrm{N}$-terminal domain and the catalytic activity of SirT1, since transfection of either SirT1 lacking the N-terminal domain or a catalytically-inactive full length SirT1 point mutant leads to only partial recovery (Vaquero et al., 2007a).

Many questions arise from these observations. Since SirT1 has never been found in the $\mathrm{HC}$ foci in immunofluorescence studies, it is unclear how SirT1 promotes H3K9 methylation in these regions. Possible explanations are that the levels of SirT1 could be so low that they fall below the threshold of immunofluorescence detection, or that the protein is only present during a very restricted time window in the cell cycle (e.g. certain stages of S-phase)-an idea supported by the massive invasion of H4K16Ac to $\mathrm{CH}$ foci upon loss of Suv39h1 and 2(Vaquero et al., 2007a). Given the obvious limitations of immunofluorescence techniques, ChIP techniques would appear to be the most appealing alternative for tracking SirT1.

Another interesting question is why loss of SirT1 only affects $50 \%$ of the MEFs. Loss of SirT1 during development may be partially covered by other HDACs. Indeed, TSA treatment of mouse L929 cells induces loss of H3K9me3 in $\mathrm{CH}$ foci, suggesting that, as in S. pombe Clr3p and CIr6p, other Class I and II HDACs might be involved and may have partial functional redun- 
dancy (Taddei et al., 2001). Another possibility is that SirT1 involvement in maintenance of $\mathrm{H} 3 \mathrm{~K} 9 \mathrm{me} 3$ levels is restricted to a certain cell cycle stage or to certain conditions. Due to the closeness of Suv39h1 to its relative Suv39h2, the effect of SirT1 may be mediated not only through the former, but also through the latter. Further studies are required to elucidate these points.

Finally, SirT1 is also involved in the degradation of the $\mathrm{H} 2 \mathrm{~A}$ variant $\mathrm{H} 2 \mathrm{~A} . \mathrm{Z}$, which is associated with active chromatin and is essential in development. Deacetylation of H2A.Z by SirT1 under cardiac hypertrophy conditions induces cell growth and inhibits apoptosis (Chen et al., 2006).

\section{SirT1 and metabolic regulation}

In addition to chromatin regulation, SirT1 is crucial to metabolism during fasting conditions, during which it is upregulated. This role actually relates to two main aspects of metabolism: firstly, through the direct control of certain enzymes of the intermediary metabolism (e.g. AceCS1, the cytosolic isoform of Acetyl-CoA synthetase involved in fatty-acid formation from acetate) (Hallows et al., 2006); and secondly, through regulation of endocrine signaling, particularly of carbohydrate and lipid metabolism. In fact, SirT1 has also been linked to the signaling of several hormone receptors such as that of the insulin-like growth factor (IGF) pathway (Lemieux et al., 2005)and those of the hepatic LXR $\alpha$ and $\beta$, androgen and glucocorticoid receptors (Amat et al., 2007; Fu et al., 2006; Li et al., 2007b). Particularly important is the role of SirT1 in glucose homeostasis, through its combined effect on the pancreas, liver, and white adipose tissue (WAT) (Amat et al., 2007; Feige and Auwerx, 2008). It promotes insulin production in pancreatic $\beta$-cells (Bordone et al., 2006; Moynihan et al., 2005), hepatic gluconeogenesis through interaction and deacetylation of the transcription regulator PGC1 $\alpha$ (Rodgers et al., 2005), and inhibition of adipogenesis and differentiation via binding to the transcriptional activator peroxisome proliferator-activated receptor $\gamma$ (PPAR $\gamma$ ) (Picard et al., 2004b).

\section{SirT1 and cell survival}

Among the functions of SirT1 that has garnered the most interest is its role in the responses to oxidative and genotoxic stress conditions (Giannakou and Partridge, 2004; Haigis and Guarente, 2006). As in the case of heterochromatin regulation, SirT1 seems to coordinate many processes such as DNA damage sensing, DNA repair and detoxifying machinery induction, inhibition of apoptosis and of senescence, cell proliferation, and autophagy stimulation. It interacts with many different factors which are often related to its transcriptional silencing capacity. This coordinated response appears to protect nerve, cardiac, liver and others types of tissues, and links SirT1 activity to cancer processes (Fig. 3).

SirT1 interacts and deacetylates key factors involved in response to stress, including the forkhead FOXO family of transcription factors (Brunet et al., 2004; Motta et al., 2004; van der Horst et al., 2004) and NF-KB (Yeung et al., 2004), by modulating their transcriptional activity. SirT1 activity induces transcriptional activation of DNA repair and DNA detoxifying machinery together with repression of cell-cycle control genes or induce apoptosis. Another interesting and not completely understood aspect of SirT1 function is its antagonism with the tumor suppressor p53, a major regulator in cell cycle control. Deacetylation of $\mathrm{p} 53$ by SirT1 inhibits p53-dependent apoptosis and senescence (Luo et al., 2001; Vaziri et al., 2001). Interestingly, SirT1/- MEFs show p53 hyperacetylation (Cheng et al., 2003) and an inhibitory effect on p53 translocation to mitochondria upon stress (Han et al., 2008).

The second level of SirT1 cell survival induction is through direct interaction and targeting of DNA repair machinery, for which two different targets have been reported to date. The first, Nijmegen breakage syndrome 1 (NBS1), is a checkpoint protein involved in DNA damage sensing and induction of DNA repair (Yuan et al., 2007). SirT1 binding and deacetylation of NBS1 induces DNA repair and cell survival. The second is the DNA repair factor Ku70, which is involved in double strand breaks (DSB) repair through non-homologous end joining (NHEJ). SirT1 binds to and deacetylates Ku70, which promotes its binding to the pro-apoptotic factor Bax. Binding to Ku70 sequesters Bax away from the mitochondria, thereby inhibiting Bax-dependent apoptosis (Cohen et al., 2004). This SirT1-Ku70 interaction might have implications in DSB repair. In fact, recent studies have shown that upon DSB breaks, SirT1 is recruited to the damaged site, an event that correlates with chromatin compaction and silencing in the same region (O'Hagan et al., 2008). This recruitment seems to be associated with SirT1 relocalization from its native loci, which induces a change in the pattern of gene expression that resembles mammalian aging (Oberdoerffer et al., 2008). However, the role of SirT1 in the process of DNA repair is now known.

The third level of regulation is through cell cycle control. SirT1 is not only involved in efficient response to environmental stress, but also in promoting cell progression. In fact, there is evidence of SirT1 downregulation upon cell-cycle exit (Sasaki et al., 2006). Although not totally understood, current data suggest that SirT1 regulates certain major players in cell cycle control, such as retinoblastoma $(\mathrm{Rb})$ and $\mathrm{E} 2 \mathrm{~F} 1$. $\mathrm{Rb}$ is a tumor suppressor that controls $G_{1}$ to $S$ transition by binding to E2F transcription factors. Cell-cycle dependent phosphorylation of $\mathrm{Rb}$ induces its binding to E2F and subsequent repression of E2F-responsive genes, thereby inducing cell cycle progression (Wong and Weber, 2007). Acetylation of $\mathrm{Rb}$ inhibits this binding; therefore suggesting that deacetylation of $\mathrm{Rb}$ by SirT1 promotes its phosphorylation and cell proliferation (Wong and Weber, 2007). In fact, Rb forms a complex with Suv39h1 and HDAC1, 2 and 3 (Vaute et al., 2002), suggesting that the SirT1 functional link between Suv39h1 may also be involved. Additionally, SirT1 binds and deacetylates E2F1, inhibiting its pro-apoptotic activity and inducing cell proliferation (Wang et al., 2006). Recent findings suggest that SirT1 can also interfere in the transcriptional repressive activity of HDAC1-containing Rbp1 complex, inhibiting its growth arrest activity (Binda et al., 2008). However, data suggest that this SirT1 induction of proliferation turns to growth arrest in chronic stress conditions, suggesting a more complex and fine-tuned mechanism of SirT1 control on cell survival (Chua et al., 2005).

Finally, very recent observations suggest that SirT1 promotes autophagy, a mechanism involved in degradation of damaged proteins and organelles resulting from stress. SirT1 1 MEFs cannot sustain autophagy activation upon stress conditions (Lee et al., 2008). However, whether this effect is direct or indirect is currently unknown.

\section{SirT1, development and cell differentiation}

In mouse ES (Embryonic stem) cells, SirT1 levels are high in 
non-differentiated cells and decrease upon differentiation (Kuzmichev et al., 2005), which suggests that SirT1 has an antagonistic relationship with differentiation. Evidence shows that SirT1 function is key in two of the most metabolically-dependent tissue types: skeletal muscle and WAT. In regular conditions, both tissues are heavy consumers of systemic glucose. Upon fasting, SirT1 upregulation induces silencing of certain key genes in both types to inhibit differentiation. In skeletal muscle, myogenin and MHC genes are silenced after SirT1 forms a complex with the transcription factor MyoD and the HAT PCAF (p300/CBP associating factor). Silencing is achieved through deacetylation of MyoD and PCAF and likely through formation of FH (Fulco et al., 2003). In WAT, SirT1 inhibits activation of genes such as fatty-acidbinding protein (aP2) through recruitment of the corepressors NCoR and SMRT to the PPAR $\gamma$-response genes, resulting in mobilization of fat as well as inhibition of WAT differentiation (Picard et al., 2004a). Recent data suggest that differentiation in nerve tissue is likewise dependent on metabolic changes and regulated by SirT1. Under oxidative stress, mouse neural progenitor cells (NPCs) stop proliferating and differentiate into astroglial cells (instead of neurons) through a SirT1-dependent mechanism (Prozorovski et al., 2008). This mechanism relies on modulation of the transcription factor Hes 1 by SirT1, which induces silencing of the pro-neuronal gene Mash1.

SirT1 is also involved in activation of differentiation in gametogenesis. Both male and female SirT $1^{-/}$knockout mice are sterile and show depletion of differentiating germ cells (McBurney et al., 2003b). However, the mechanisms involved are currently unknown.

\section{SirT2}

SirT2 is a type I sirtuin like its yeast ortholog Hst2p, and is located in the cytoplasm except during the $G_{2}$ to $M$ transition, when it is transported to the nucleus and localizes to chromatin (North and Verdin, 2007a, Vaquero et al., 2006). Although many aspects of SirT2 function remain unknown, all evidence suggests that it participates in cell cycle control, particularly at the $G_{2}$ to $M$ checkpoint. Interestingly, SirT2 overexpression delays mitosis exit and shortens $G_{1}$ (Bae et al., 2004; Dryden et al., 2003), whereas $\mathrm{SirT2}^{-/-}$MEFs are associated with longer $\mathrm{G}_{1}$ and shorter S-phase (Vaquero et al., 2006). Data suggest that the levels, activity and localization of SirT2 are tightly regulated by phosphorylation (Dryden et al., 2003; North and Verdin, 2007b). In contrast to SirT1, which is associated with cell survival and cancer processes, SirT2 acts as a tumor suppressor (Inoue et al., 2007). Overexpression of mammalian SirT2 under conditions of uncontrolled proliferation or mitotic stress promotes cell cycle arrest before mitotic entry (Inoue et al., 2007), and overexpression of either SirT2 or Hst2p in starfish oocytes delays cell division (Borra et al., 2002). Consistent with this, SirT2 is downregulated in certain cancers (e.g. glial and gastric carcinomas) (Hiratsuka et al., 2003; Inoue et al., 2007) and it has been found mutated in melanomas. (Lennerz et al., 2005)

Like SirT1, SirT2 has also been linked to inhibition of differentiation of adipocyte and neural oligodendroglial cells (Jing et al., 2007; Li et al., 2007a). Furthermore, SirT2 has also been imputed in neurodegenerative diseases like SirT1, but apparently with an opposite role which is not understood (Outeiro et al., 2007).

So far, two major targets have been described for SirT2: chromatin and the cytoskeleton.

Despite its cytosolic localization, SirT2 has histone deacetylase activity-highly specific for H4K16Ac, and to a lesser extent, H3K9Ac-, and in RNAi experiments, loss of SirT2 leads to high levels of H4K16Ac (Vaquero et al., 2006). SirT2 is responsible for the global drop of $\mathrm{H} 4 \mathrm{~K} 16 \mathrm{Ac}$ levels just before mitosis, which may promote proper compaction of chromosomes during mitosis. Given that H4K16Ac shows a unique capacity to inhibit the formation of high orders of chromatin organization (ShogrenKnaak et al., 2006), its removal should be necessary for the cell cycle to proceed. However, SirT2-/- MEFs, which show hyperacetylation of H4K16 during mitosis, do not exhibit any clear delay in mitosis progression, but do show a delay in S-phase entry (Vaquero et al., 2006). This might suggest that any possible defect in chromatin produced by mitotic progression in the presence of H4K16 hyperacetylation might pay a toll in S-phase entry, when the $G_{1} / S$ checkpoint needs to decide whether to proceed with DNA replication. The source of this defect is unknown, but it could involve DNA repair processes, given that the main $\mathrm{H} 4 \mathrm{~K} 16$ acetyltransferase in mammalian cells, MOF (Gupta et al., 2008; Taipale et al., 2005), is associated with DNA damage-sensing machinery and key elements of the $G_{1}$ to $S$ checkpoint (e.g. p53) (Gupta et al., 2005). Considering that global levels of H4K16Ac peak during S-phase and that this modification has been involved in histone deposition in plants (Belyaev et al., 1997), there is clearly a close but unexplained relationship between H4K16Ac and the S-phase. Further studies should clarify whether the cell cycle defects described upon SirT2 loss are completely related to aberrant H4K16Ac levels or to other possible targets.

The other known SirT2 target described so far is $\alpha$-tubulin, whose deacetylation has been hypothesized to be important for regulation of microtubule dynamics (North et al., 2003). Since tubulin acetylation seems to stabilize microtubule structures, deacetylation might disrupt it and consequently inhibit cell progression (Piperno et al., 1987). SirT2 has actually been found to interact with another tubulin deacetylase, HDAC6, but the implications of this finding are not completely understood (North et al., 2003).

\section{SirT3}

SirT3 is a close relative of SirT2, is phylogenetically related to Hst2p and is the only sirtuin directly involved in human longevity (Rose et al., 2003). It is present mainly in the mitochondria, to which it is translocated upon cleavage of 142 residues from its $N$ terminus (Onyango et al., 2002; Schwer et al., 2002). The cellular role of SirT3 is related to metabolism and mitochondrial function, although it is not clearly understood. Despite the fact that SirT3 loss has been shown to produce general hyperacetylation of mitochondrial proteins (Lombard et al., 2007) and to interact with the Foxo factor Foxo3a (Jacobs et al., 2008), only one target has been described to date: acetyl-CoA synthetase 2 (AceCS2) (Hallows et al., 2006; Schwer et al., 2006). Mitochondrial AceCS2 is activated upon deacetylation by SirT3, inducing the production of Acetyl-CoA (Ac-CoA), which in turn causes the mitochondrial metabolic rate to increase. Although widely expressed, SirT3 is particularly important in brown adipocyte tissue (BAT), brain and kidney, but is very poorly expressed in WAT (Shi et al., 2005).

Surprisingly, SirT3 might have a function in chromatin regulation. Like SirT2, SirT3 shows strong histone deacetylation activity 
specific for H4K16Ac and H3K9Ac (Scher et al., 2007). Moreover, some full-length SirT3 resides in the nucleus in certain uncharacterized foci. SirT3 transfection in human embryonic 293 cells can induce silencing of a reporter gene integrated into euchromatic regions through deacetylation of H4K16Ac and H3K9Ac in promoter regions. However, in contrast to loss of SirT2, loss of SirT3 does not correlate with a global increase of $\mathrm{H} 4 \mathrm{~K} 16 \mathrm{Ac}$ or H3K9Ac, suggesting that, if indeed involved in transcriptional regulation, it might only target a small subset of genes. However, no candidate genes have yet been identified.

Stress conditions induced by DNA damaging agents such as Etoposide and UV radiation, as well as SirT3 overexpression, induce extensive relocalization of SirT3 from the nucleus to mitochondria for an unknown function (Scher et al., 2007). Nuclear SirT3 might represent a different functional population than the majority present in the mitochondria; hence, translocation to mitochondria might imply new roles, such as the described involvement of SirT3 in apoptosis (Allison and Milner, 2007). Another possibility is that, as with SirT2, SirT3 levels require very tight regulation, and translocation to mitochondria might overcome a certain threshold beyond which specific responses might occur. A nuclear shuttling mechanism, like the recently described for SirT2, has been hypothesized for SirT3 to support these observations. It is based on the fact that leptomycin A can block the translocation (Scher et al., 2007). Other data suggest that overexpression of another mitochondrial sirtuin, SirT5, induces nuclear accumulation of SirT3 through a completely unknown mechanism (Nakamura et al., 2008).

\section{SirT4 and SirT5}

SirT4 is a mitochondrial Type II sirtuin involved in ADPribosylation of mitochondrial proteins and does not have any deacetylase activity or any described role in chromatin. In contrast, it seems to have a role in metabolic control and insulin production in pancreatic $\beta$-cells via modulation of the activity of glutamate dehydrogenase (GDH), which is involved in the catabolism of glutamic acid and glutamine (Haigis et al., 2006).

SirT5 is a Type III sirtuin related to the prokaryotic sirtuins. Its function remains unknown.

\section{SirT6}

SirT6 is a Type IV nuclear chromatin-bound sirtuin essential for viability (Mostoslavsky et al., 2006). Its loss is associated with genomic instability, increased sensitivity to ionizing radiation (IR), and both oxidative and genotoxic stress, which lead to lifespan shortening and an aging-like phenotype. SirT6 is functionally associated with base excision repair (BER), a DNA repair mechanism responsible for single-stranded break repairs (Mostoslavsky et al., 2006). However, it is unclear whether this involvement is direct, since SirT6 does not seem to localize to BER foci, and its loss does not impair BER mechanism. SirT6 actually binds to GCIP, a putative tumor suppressor and a cell proliferation inhibitor, which suggests that SirT6 might have more of a role in sensing and signaling DNA repair and in certain conditions of growth arrest (Ma et al., 2007). In agreement with this role, a recent report described a positive role for p53 in the control of SirT6 protein levels in normal growth conditions (Kanfi et al., 2008). Interestingly, SirT6 levels are also upregulated in caloric restriction or nutrient deprivation conditions (Kanfi et al., 2008), which together with the evidence described above support a role for SirT6 in oxidative stress response.

SirT6 was originally found to show strong ADPribosyltransferase activity, but no other target was described except itself. However, SirT6 has also recently been observed in telomeric regions, where it seems to exhibit very specific H3K9Ac deacetylase activity (Michishita et al., 2008). SirT6 loss induces hyperacetylation of $\mathrm{H} 3 \mathrm{~K} 9 \mathrm{Ac}$ as well as telomeric defects such as end-to-end chromosomal fusions, leading to senescence. Additionally, SirT6 is involved in the telomeric localization of Werner syndrome gene protein (WRN), a DNA helicase involved in telomeric replication during S-phase that also interacts with SirT1 (Narala et al., 2008). This body of evidence suggests that SirT6 is involved in ensuring proper telomeric replication. However, how these data correlate with the previously described functional link to DNA repair, and how the H3K9Ac deacetylation activity of SirT6 participates in these functions, are unknown.

\section{SirT7}

SirT7, the other Type IV mammalian sirtuin, is located in the nucleolus and seems to have major ADP-ribosylation activity (Michishita et al., 2005). Surprisingly, it does not seem to be implicated in rDNA silencing; instead, it appears to directly activate RNA polymerase-I. Loss of SirT7 produces a loss of RNA-polymerase I bound to the rDNA regions, inducing inhibition of cell proliferation and apoptosis (Ford et al., 2006). This role is dependent on SirT7 catalytic activity, but no targets have been described to date. In contrast, SirT7 ${ }^{-/-}$mice show heart hypertrophy and inflammatory cardiopathy as well as a significant loss of resistance capacity to stress (Vakhrusheva et al., 2008). How these observations are related to the SirT7 role in nucleolar rDNA regulation is now known and should be addressed in the future.

Interestingly, the other sirtuin found in the nucleolus, SirT1, has an antagonistic role to SirT7: it binds to rDNA copies through interaction with DNA-methyltransferase Dnmt1 and participates in silencing of these regions (Espada et al., 2007). In addition to histones, SirT1 also inhibits RNA polymerase-I by deacetylating the basal factor TAF,67 (Muth et al., 2001). To date, the functional relationship between these two sirtuins is unknown.

\section{Conclusions}

The relevance of sirtuins to chromatin in archaea to humans makes them exceptional witnesses of the path followed by chromatin regulation and reflects the importance of chromatin functions in metabolism and stress adaptation. Despite this, the conserved role of sirtuins in chromatin dynamics has not garnered the same attention as most of the newly acquired sirtuin functions (e.g. cell survival under stress), and in particular in the context of human pathologies such as cancer and neurodegenerative diseases. Interestingly, a growing body of evidence suggests that in a significant number of these new functions, the main effect of sirtuins is exerted via a direct effect on chromatin. Elucidating sirtuins' roles in chromatin is not only relevant to understanding said pathologies, but also to explaining the evolution and specialization of these proteins. Next years should be crucial to build a more complete and integrated 
perspective of all described sirtuin roles into a more accurate description of sirtuin global contribution to cell life basic functions.

\section{Acknowledgements}

The author wishes to apologize to many colleagues whose work could not be cited in this review due to space limitations. Many thanks to Dr. Alfred Cortés, Dr. Ethelvina Queralt, Dr. Patrick Trojer and Dr. Danny Reinberg for their helpful suggestions and valuable contributions to this manuscript. The work of my lab is supported by the Spanish Ministry of Science and Innovation (MICINN), ICREA, Institut Català d'Oncologia (ICO) and European Community Marie Curie International Reintegration Grant MIRG-CT-046533.

\section{References}

AHRINGER, J. (2000). NuRD and SIN3 histone deacetylase complexes in development. Trends Genet 16: 351-356.

ALSFORD, S., KAWAHARA, T., ISAMAH, C. and HORN, D. (2007). A sirtuin in the African trypanosome is involved in both DNA repair and telomeric gene silencing but is not required for antigenic variation. Mol Microbiol 63: 724-736.

ALLISON, S.J. and MILNER, J. (2007). SIRT3 is pro-apoptotic and participates in distinct basal apoptotic pathways. Cell Cycle 6: 2669-2677.

AMAT, R., SOLANES, G., GIRALT, M. and VILLARROYA, F. (2007). SIRT1 is involved in glucocorticoid-mediated control of uncoupling protein-3 gene transcription. J Biol Chem 282: 34066-34076.

APARICIO, O.M., BILLINGTON, B.L. and GOTTSCHLING, D.E. (1991). Modifiers of position effect are shared between telomeric and silent mating-type loci in S. cerevisiae. Cell 66: 1279-1287.

ASTROM, S.U., CLINE, T.W. and RINE, J. (2003). The Drosophila melanogaster sir2+ gene is nonessential and has only minor effects on position-effect variegation. Genetics 163: 931-937.

BAE, N.S., SWANSON, M.J., VASSILEV, A. and HOWARD, B.H. (2004). Human histone deacetylase SIRT2 interacts with the homeobox transcription factor HOXA10. J Biochem (Tokyo) 135: 695-700.

BATES, E.A., VICTOR, M., JONES, A.K., SHI, Y. and HART, A.C. (2006). Differential contributions of Caenorhabditis elegans histone deacetylases to huntingtin polyglutamine toxicity. J Neurosci 26: 2830-2838.

BEDALOV, A., HIRAO, M., POSAKONY, J., NELSON, M. and SIMON, J.A. (2003). NAD+-dependent deacetylase Hst1p controls biosynthesis and cellular NAD+ levels in Saccharomyces cerevisiae. Mol Cell Biol 23: 7044-7054.

BELENKY, P., RACETTE, F.G., BOGAN, K.L., MCCLURE, J.M., SMITH, J.S. and BRENNER, C. (2007). Nicotinamide riboside promotes Sir2 silencing and extends lifespan via Nrk and Urh1/Pnp1/Meu1 pathways to NAD+. Cell 129: 473-484.

BELYAEV, N.D., HOUBEN, A., BARANCZEWSKI, P. and SCHUBERT, I. (1997). Histone $\mathrm{H} 4$ acetylation in plant heterochromatin is altered during the cell cycle. Chromosoma 106: 193-197.

BELL, S.D., BOTTING, C.H., WARDLEWORTH, B.N., JACKSON, S.P. and WHITE, M.F. (2002). The interaction of Alba, a conserved archaeal chromatin protein, with Sir2 and its regulation by acetylation. Science 296: 148-151.

BERDICHEVSKY, A., VISWANATHAN, M., HORVITZ, H.R. and GUARENTE, L. (2006). C. elegans SIR-2.1 interacts with 14-3-3 proteins to activate DAF-16 and extend life span. Cell 125: 1165-1177.

BERNANDER, R. (2003). The archaeal cell cycle: current issues. Mol Microbiol 48 : 599-604.

BIANCHI-FRIAS, D., ORIAN, A., DELROW, J.J., VAZQUEZ, J., ROSALES-NIEVES, A.E. and PARKHURST, S.M. (2004). Hairy transcriptional repression targets and cofactor recruitment in Drosophila. PLoS Biol 2: E178.

BINDA, O., NASSIF, C. and BRANTON, P.E. (2008). SIRT1 negatively regulates HDAC1-dependent transcriptional repression by the RBP1 family of proteins. Oncogene 27: 3384-3392.

BITTERMAN, K.J., ANDERSON, R.M., COHEN, H.Y., LATORRE-ESTEVES, M. and SINCLAIR, D.A. (2002). Inhibition of silencing and accelerated aging by nicotinamide, a putative negative regulator of yeast sir2 and human SIRT1. $J$ Biol Chem 277: 45099-45107.

BOILY, G., SEIFERT, E.L., BEVILACQUA, L., HE, X.H., SABOURIN, G., ESTEY C., MOFFAT, C., CRAWFORD, S., SALIBA, S., JARDINE, K. et al. (2008). SirT1 regulates energy metabolism and response to caloric restriction in mice. PLOS ONE 3: e1759.

BORDONE, L., MOTTA, M.C., PICARD, F., ROBINSON, A., JHALA, U.S., APFELD, J., MCDONAGH, T., LEMIEUX, M., MCBURNEY, M., SZILVASI, A. et al. (2006). Sirt1 regulates insulin secretion by repressing UCP2 in pancreatic beta cells. PLOS Biol 4: e31.

BORRA, M.T., O'NEILL, F.J., JACKSON, M.D., MARSHALL, B., VERDIN, E., FOLTZ, K.R. and DENU, J.M. (2002). Conserved enzymatic production and biological effect of O-acetyl-ADP-ribose by silent information regulator 2-like NAD+-dependent deacetylases. J Biol Chem 277: 12632-12641.

BRUNET, A., SWEENEY, L.B., STURGILL, J.F., CHUA, K.F., GREER, P.L., LIN Y., TRAN, H., ROSS, S.E., MOSTOSLAVSKY, R., COHEN, H.Y. et al. (2004). Stress-dependent regulation of FOXO transcription factors by the SIRT1 deacetylase. Science 303: 2011-2015.

BUCK, S.W., GALLO, C.M. and SMITH, J.S. (2004). Diversity in the Sir2 family of protein deacetylases. J Leukoc Biol 75: 939-950.

CELIC, I., MASUMOTO, H., GRIFFITH, W.P., MELUH, P., COTTER, R.J., BOEKE, J.D. and VERREAULT, A. (2006). The sirtuins hst 3 and Hst4p preserve genome integrity by controlling histone h3 lysine 56 deacetylation. Curr Biol 16: 12801289

COHEN, H.Y., MILLER, C., BITTERMAN, K.J., WALL, N.R., HEKKING, B., KESSLER, B., HOWITZ, K.T., GOROSPE, M., DE CABO, R. and SINCLAIR, D.A. (2004). Calorie restriction promotes mammalian cell survival by inducing the SIRT1 deacetylase. Science 305: 390-392.

CRAIG, J.M. (2005). Heterochromatin—many flavours, common themes. Bioessays 27: 17-28.

CHEN, I.Y., LYPOWY, J., PAIN, J., SAYED, D., GRINBERG, S., ALCENDOR, R.R. SADOSHIMA, J. and ABDELLATIF, M. (2006). Histone H2A.Z is essential for cardiac myocyte hypertrophy but opposed by silent information regulator 2alpha. J Biol Chem 281: 19369-19377.

CHENG, H.L., MOSTOSLAVSKY, R., SAITO, S., MANIS, J.P., GU, Y., PATEL, P., BRONSON, R., APPELLA, E., ALT, F.W. and CHUA, K.F. (2003). Developmental defects and p53 hyperacetylation in Sir2 homolog (SIRT1)-deficient mice. Proc Natl Acad Sci USA 100: 10794-10799.

CHUA, K.F., MOSTOSLAVSKY, R., LOMBARD, D.B., PANG, W.W., SAITO, S. FRANCO, S., KAUSHAL, D., CHENG, H.L., FISCHER, M.R., STOKES, N. et al. (2005). Mammalian SIRT1 limits replicative life span in response to chronic genotoxic stress. Cell Metab 2: 67-76.

D'INCALCI, M., ALLAVENA, P., WU, R.S. and BONNER, W.M. (1986). H1 varian synthesis in proliferating and quiescent human cells. Eur J Biochem 154: 273 279.

DAUJAT, S., ZEISSLER, U., WALDMANN, T., HAPPEL, N. and SCHNEIDER, R (2005). HP1 binds specifically to Lys26-methylated histone H1.4, whereas simultaneous Ser27 phosphorylation blocks HP1 binding. J Biol Chem 280 38090-38095.

DE RUIJTER, A.J., VAN GENNIP, A.H., CARON, H.N., KEMP, S. and VAN KUILENBURG, A.B. (2003). Histone deacetylases (HDACs): characterization of the classical HDAC family. Biochem J 370: 737-749.

DRYDEN, S.C., NAHHAS, F.A., NOWAK, J.E., GOUSTIN, A.S. and TAINSKY, M.A. (2003). Role for human SIRT2 NAD-dependent deacetylase activity in control of mitotic exit in the cell cycle. Mol Cell Biol 23: 3173-3185.

DURAISINGH, M.T., VOSS, T.S., MARTY, A.J., DUFFY, M.F., GOOD, R.T. THOMPSON, J.K., FREITAS-JUNIOR, L.H., SCHERF, A., CRABB, B.S. and COWMAN, A.F. (2005). Heterochromatin silencing and locus repositioning linked to regulation of virulence genes in Plasmodium falciparum. Cell 121: 1324.

DURAND-DUBIEF, M., SINHA, I., FAGERSTROM-BILLAI, F., BONILLA, C., WRIGHT, A., GRUNSTEIN, M. and EKWALL, K. (2007). Specific functions for the fission yeast Sirtuins $\mathrm{Hst} 2$ and $\mathrm{Hst} 4$ in gene regulation and retrotransposon silencing. EMBO J 26: 2477-2488.

EISSENBERG, J.C. and SHILATIFARD, A. (2006). Leaving a mark: the many footprints of the elongating RNA polymerase II. Curr Opin Genet Dev 16: 184- 
190.

EKWALL, K. (2005). Genome-wide analysis of HDAC function. Trends Genet 21: 608-615.

ESPADA, J., BALLESTAR, E., SANTORO, R., FRAGA, M.F., VILLAR-GAREA, A. NEMETH, A., LOPEZ-SERRA, L., ROPERO, S., ARANDA, A., OROZCO, H. et al. (2007). Epigenetic disruption of ribosomal RNA genes and nucleolar architecture in DNA methyltransferase 1 (Dnmt1) deficient cells. Nucleic Acids Res 35: $2191-2198$

ESTELLER, M. (2007). Cancer epigenomics: DNA methylomes and histonemodification maps. Nat Rev Genet 8: 286-298.

FEIGE, J.N. and AUWERX, J. (2008). Transcriptional targets of sirtuins in the coordination of mammalian physiology. Curr Opin Cell Biol 20: 303-309.

FENG, Q., WANG, H., NG, H.H., ERDJUMENT-BROMAGE, H., TEMPST, P., STRUHL, K. and ZHANG, Y. (2002). Methylation of H3-lysine 79 is mediated by a new family of HMTases without a SET domain. Curr Biol 12: 1052-1058.

FINNIN, M.S., DONIGIAN, J.R. and PAVLETICH, N.P. (2001). Structure of the histone deacetylase SIRT2. Nat Struct Biol 8: 621-625.

FORD, E., VOIT, R., LISZT, G., MAGIN, C., GRUMMT, I. and GUARENTE, L. (2006). Mammalian Sir2 homolog SIRT7 is an activator of RNA polymerase I transcription. Genes Dev 20: 1075-1080.

FREEMAN-COOK, L.L., GOMEZ, E.B., SPEDALE, E.J., MARLETT, J., FORSBURG, S.L., PILLUS, L. and LAURENSON, P. (2005). Conserved locus-specific silencing functions of Schizosaccharomyces pombe sir2+. Genetics 169: 12431260.

FREITAS-JUNIOR, L.H., HERNANDEZ-RIVAS, R., RALPH, S.A., MONTIELCONDADO, D., RUVALCABA-SALAZAR, O.K., ROJAS-MEZA, A.P., MANCIOSILVA, L., LEAL-SILVESTRE, R.J., GONTIJO, A.M., SHORTE, S. et al. (2005). Telomeric heterochromatin propagation and histone acetylation control mutually exclusive expression of antigenic variation genes in malaria parasites. Cell 121: $25-36$

FRYE, R.A. (1999). Characterization of five human cDNAs with homology to the yeast SIR2 gene: Sir2-like proteins (sirtuins) metabolize NAD and may have protein ADP-ribosyltransferase activity. Biochem Biophys Res Commun 260: 273-279.

FRYE, R.A. (2000). Phylogenetic classification of prokaryotic and eukaryotic Sir2like proteins. Biochem Biophys Res Commun 273: 793-798.

FU, M., LIU, M., SAUVE, A.A., JIAO, X., ZHANG, X., WU, X., POWELL, M.J., YANG, T., GU, W., AVANTAGGIATI, M.L. et al. (2006). Hormonal control of androgen receptor function through SIRT1. Mol Cell Biol 26: 8122-8135.

FUKS, F., HURD, P.J., DEPLUS, R. and KOUZARIDES, T. (2003). The DNA methyltransferases associate with HP1 and the SUV39H1 histone methyltransferase. Nucleic Acids Res 31: 2305-2312.

FULCO, M., SCHILTZ, R.L., IEZZI, S., KING, M.T., ZHAO, P., KASHIWAYA, Y., HOFFMAN, E., VEECH, R.L. and SARTORELLI, V. (2003). Sir2 regulates skeletal muscle differentiation as a potential sensor of the redox state. Mol Cell 12: 51-62.

FURUYAMA, T., BANERJEE, R., BREEN, T.R. and HARTE, P.J. (2004). SIR2 is required for polycomb silencing and is associated with an $E(Z)$ histone methyltransferase complex. Curr Biol 14: 1812-1821.

GARCIA-SALCEDO, J.A., GIJON, P., NOLAN, D.P., TEBABI, P. and PAYS, E. (2003). A chromosomal SIR2 homologue with both histone NAD-dependent ADP-ribosyltransferase and deacetylase activities is involved in DNA repair in Trypanosoma brucei. EMBO J 22: 5851-5862.

GARDNER, M.J., HALL, N., FUNG, E., WHITE, O., BERRIMAN, M., HYMAN, R.W., CARLTON, J.M., PAIN, A., NELSON, K.E., BOWMAN, S. et al. (2002). Genome sequence of the human malaria parasite Plasmodium falciparum. Nature 419: 498-511.

GARTENBERG, M.R. (2000). The Sir proteins of Saccharomyces cerevisiae: mediators of transcriptional silencing and much more. Curr Opin Microbiol 3: 132-137.

GIANNAKOU, M.E. and PARTRIDGE, L. (2004). The interaction between FOXO and SIRT1: tipping the balance towards survival. Trends Cell Biol 14: 408-412.

GLOZAK, M.A., SENGUPTA, N., ZHANG, X. and SETO, E. (2005). Acetylation and deacetylation of non-histone proteins. Gene 363: 15-23.

GOTTLIEB, S. and ESPOSITO, R.E. (1989). A new role for a yeast transcriptional silencer gene, SIR2, in regulation of recombination in ribosomal DNA. Cell 56: 771-776.

GREWAL, S.I. and JIA, S. (2007). Heterochromatin revisited. Nat Rev Genet 8: 3546.

GRUNSTEIN, M. (1997). Molecular model for telomeric heterochromatin in yeast. Curr Opin Cell Biol 9: 383-387.

GUARENTE, L. (2000). Sir2 links chromatin silencing, metabolism, and aging. Genes Dev 14: 1021-1026.

GUPTA, A., SHARMA, G.G., YOUNG, C.S., AGARWAL, M., SMITH, E.R., PAULL, T.T., LUCCHESI, J.C., KHANNA, K.K., LUDWIG, T. and PANDITA, T.K. (2005) Involvement of human MOF in ATM function. Mol Cell Biol 25: 5292-5305.

GUPTA, A., GUERIN-PEYROU, T.G., SHARMA, G.G., PARK, C., AGARWAL, M., GANJU, R.K., PANDITA, S., CHOI, K., SUKUMAR, S., PANDITA, R.K. et al. (2008). The mammalian ortholog of Drosophila MOF that acetylates histone $\mathrm{H} 4$ lysine 16 is essential for embryogenesis and oncogenesis. Mol Cell Biol28: 397409.

HAIGIS, M.C. and GUARENTE, L.P. (2006). Mammalian sirtuins-emerging roles in physiology, aging, and calorie restriction. Genes Dev 20: 2913-2921.

HAIGIS, M.C., MOSTOSLAVSKY, R., HAIGIS, K.M., FAHIE, K., CHRISTODOULOU, D.C., MURPHY, A.J., VALENZUELA, D.M., YANCOPOULOS, G.D., KAROW, M., BLANDER, G. et al. (2006). SIRT4 inhibits glutamate dehydrogenase and opposes the effects of calorie restriction in pancreatic beta cells. Cell 126: 941954.

HALDAR, D. and KAMAKAKA, R.T. (2008). Schizosaccharomyces pombe Hst4 functions in DNA damage response by regulating histone $\mathrm{H} 3 \mathrm{~K} 56$ acetylation. Eukaryot Cell 7: 800-813.

HALME, A., BUMGARNER, S., STYLES, C. and FINK, G.R. (2004). Genetic and epigenetic regulation of the FLO gene family generates cell-surface variation in yeast. Cell 116: 405-415.

HALLOWS, W.C., LEE, S. and DENU, J.M. (2006). Sirtuins deacetylate and activate mammalian acetyl-CoA synthetases. Proc Natl Acad Sci USA 103: 10230-10235.

HAN, M.K., SONG, E.K., GUO, Y., OU, X., MANTEL, C. and BROXMEYER, H.E. (2008). SIRT1 regulates apoptosis and Nanog expression in mouse embryonic stem cells by controlling p53 subcellular localization. Cell Stem Cell 2: 241-251.

HANSEN, J.C. (2002). Conformational dynamics of the chromatin fiber in solution: determinants, mechanisms, and functions. Annu Rev Biophys Biomol Struct 31: 361-392.

HICKMAN, M.A. and RUSCHE, L.N. (2007). Substitution as a mechanism for genetic robustness: the duplicated deacetylases Hst1p and Sir2p in Saccharomyces cerevisiae. PLoS Genet 3: e126.

HIRATSUKA, M., INOUE, T., TODA, T., KIMURA, N., SHIRAYOSHI, Y., KAMITANI, H., WATANABE, T., OHAMA, E., TAHIMIC, C.G., KURIMASA, A. et al. (2003) Proteomics-based identification of differentially expressed genes in human gliomas: down-regulation of SIRT2 gene. Biochem Biophys Res Commun 309 558-566.

HOGAN, E. and KOSHLAND, D. (1992). Addition of extra origins of replication to a minichromosome suppresses its mitotic loss in cdc6 and cdc14 mutants of Saccharomyces cerevisiae. Proc Natl Acad Sci USA 89: 3098-3102.

HUANG, J. and MOAZED, D. (2003). Association of the RENT complex with nontranscribed and coding regions of rDNA and a regional requirement for the replication fork block protein Fob1 in rDNA silencing. Genes Dev17:2162-2176.

IMAI, S., ARMSTRONG, C.M., KAEBERLEIN, M. and GUARENTE, L. (2000). Transcriptional silencing and longevity protein Sir2 is an NAD-dependent histone deacetylase. Nature 403: 795-800.

INOUE, T., HIRATSUKA, M., OSAKI, M., YAMADA, H., KISHIMOTO, I., YAMAGUCHI, S., NAKANO, S., KATOH, M., ITO, H. and OSHIMURA, M. (2007). SIRT2, a tubulin deacetylase, acts to block the entry to chromosome condensation in response to mitotic stress. Oncogene 26: 945-957.

JACOBS, K.M., PENNINGTON, J.D., BISHT, K.S., AYKIN-BURNS, N. KIM, H.S., MISHRA, M., SUN, L., NGUYEN, P., AHN, B.H., LECLERC, J., DENG, C.X.,SPITZ, D.R. and GIUS, D. (2008). SIRT3 interacts with the daf-16 homolog FOXO3a in the mitochondria, as well as increases FOXO3a dependent gene expression. Int J Biol Sci 4: 291-299.

JEDRUSIK, M.A. and SCHULZE, E. (2003). Telomeric position effect variegation in Saccharomyces cerevisiae by Caenorhabditis elegans linker histones sug- 
gests a mechanistic connection between germ line and telomeric silencing. $\mathrm{Mol}$ Cell Biol 23: 3681-3691.

JEDRUSIK, M.A. and SCHULZE, E. (2007). Linker histone HIS-24 (H1.1) cytoplasmic retention promotes germ line development and influences histone $\mathrm{H} 3$ methylation in Caenorhabditis elegans. Mol Cell Biol 27: 2229-2239.

JING, E., GESTA, S. and KAHN, C.R. (2007). SIRT2 regulates adipocyte differentiation through FoxO1 acetylation/deacetylation. Cell Metab 6: 105-114.

KANFI, Y., SHALMAN, R., PESHTI, V., PILOSOF, S.N., GOZLAN, Y.M., PEARSON, K.J., LERRER, B., MOAZED, D., MARINE, J.C., DE CABO, R. et al. (2008). Regulation of SIRT6 protein levels by nutrient availability. FEBS Lett 582: 543548.

KIM, E.J., KHO, J.H., KANG, M.R. and UM, S.J. (2007). Active regulator of SIRT1 cooperates with SIRT1 and facilitates suppression of p53 activity. Mol Cell 28: 277-290.

KIM, J.E., CHEN, J. and LOU, Z. (2008). DBC1 is a negative regulator of SIRT1. Nature 451: 583-586.

KIMURA, A., UMEHARA, T. and HORIKOSHI, M. (2002). Chromosomal gradient of histone acetylation established by Sas $2 p$ and Sir2 $p$ functions as a shield against gene silencing. Nat Genet 32: 370-377.

KLOSE, R.J., GARDNER, K.E., LIANG, G., ERDJUMENT-BROMAGE, H., TEMPST, P. and ZHANG, Y. (2007). Demethylation of histone H3K36 and H3K9 by Rph1: a vestige of an H3K9 methylation system in Saccharomyces cerevisiae? Mol Cell Biol 27: 3951-3961.

KORNBERG, R.D. and LORCH, Y. (1999). Twenty-five years of the nucleosome, fundamental particle of the eukaryote chromosome. Cell 98: 285-294.

KOUSKOUTI, A. and TALIANIDIS, I. (2005). Histone modifications defining active genes persist after transcriptional and mitotic inactivation. EMBO J24:347-357.

KRAUSS, V. (2008). Glimpses of evolution: heterochromatic histone H3K9 methyltransferases left its marks behind. Genetica 133: 93-106.

KURDISTANI, S.K. and GRUNSTEIN, M. (2003). Histone acetylation and deacetylation in yeast. Nat Rev Mol Cell Biol 4: 276-284.

KURDISTANI, S.K., TAVAZOIE, S. and GRUNSTEIN, M. (2004). Mapping global histone acetylation patterns to gene expression. Cell 117: 721-733.

KUSTATSCHER, G., HOTHORN, M., PUGIEUX, C., SCHEFFZEK, K. and LADURNER, A.G. (2005). Splicing regulates NAD metabolite binding to histone macroH2A. Nat Struct Mol Biol 12: 624-625.

KUZMICHEV, A., JENUWEIN, T., TEMPST, P. and REINBERG, D. (2004). Different $E Z H 2$-containing complexes target methylation of histone $\mathrm{H} 1$ or nucleosomal histone H3. Mol Cell 14: 183-193.

KUZMICHEV, A., MARGUERON, R., VAQUERO, A., PREISSNER, T.S., SCHER, M., KIRMIZIS, A., OUYANG, X., BROCKDORFF, N., ABATE-SHEN, C., FARNHAM, P. et al. (2005). Composition and histone substrates of polycomb repressive group complexes change during cellular differentiation. Proc Natl Acad Sci USA 102: 1859-1864.

LACHNER, M. and JENUWEIN, T. (2002). The many faces of histone lysine methylation. Curr Opin Cell Biol 14: 286-298.

LAMMING, D.W., LATORRE-ESTEVES, M., MEDVEDIK, O., WONG, S.N., TSANG, F.A., WANG, C., LIN, S.J. and SINCLAIR, D.A. (2005). HST2 mediates SIR2independent life-span extension by calorie restriction. Science 309: 1861-1864.

LANDRY, J., SUTTON, A., TAFROV, S.T., HELLER, R.C., STEBBINS, J., PILLUS, L. and STERNGLANZ, R. (2000). The silencing protein SIR2 and its homologs are NAD-dependent protein deacetylases. Proc Natl Acad Sci USA 97: 58071581.

LEE, I.H., CAO, L., MOSTOSLAVSKY, R., LOMBARD, D.B., LIU, J., BRUNS, N.E., TSOKOS, M., ALT, F.W. and FINKEL, T. (2008). A role for the NAD-dependent deacetylase Sirt1 in the regulation of autophagy. Proc Natl Acad Sci USA 105: 3374-3379.

LEMIEUX, M.E., YANG, X., JARDINE, K., HE, X., JACOBSEN, K.X., STAINES, W.A., HARPER, M.E. and MCBURNEY, M.W. (2005). The Sirt1 deacetylase modulates the insulin-like growth factor signaling pathway in mammals. Mech Ageing Dev 126: 1097-1105.

LENNERZ, V., FATHO, M., GENTILINI, C., FRYE, R.A., LIFKE, A., FEREL, D., WOLFEL, C., HUBER, C. and WOLFEL, T. (2005). The response of autologous $\mathrm{T}$ cells to a human melanoma is dominated by mutated neoantigens. Proc Natl Acad Sci USA 102: 16013-16018.
LI, W., ZHANG, B., TANG, J., CAO, Q., WU, Y., WU, C., GUO, J., LING, E.A. and LIANG, F. (2007a). Sirtuin 2, a mammalian homolog of yeast silent information regulator-2 longevity regulator, is an oligodendroglial protein that decelerates cell differentiation through deacetylating alpha-tubulin. J Neurosci 27: 26062616.

LI, X., ZHANG, S., BLANDER, G., TSE, J.G., KRIEGER, M. and GUARENTE, L. (2007b). SIRT1 deacetylates and positively regulates the nuclear receptor $L X R$ Mol Cell 28: 91-106.

LIEB, J.D., LIU, X., BOTSTEIN, D. and BROWN, P.O. (2001). Promoter-specific binding of Rap1 revealed by genome-wide maps of protein-DNA association. Nat Genet 28: 327-334.

LIOU, G.G., TANNY, J.C., KRUGER, R.G., WALZ, T. and MOAZED, D. (2005). Assembly of the SIR complex and its regulation by O-acetyl-ADP-ribose, a product of NAD-dependent histone deacetylation. Cell 121: 515-527.

LOMBARD, D.B., ALT, F.W., CHENG, H.L., BUNKENBORG, J., STREEPER, R.S., MOSTOSLAVSKY, R., KIM, J., YANCOPOULOS, G., VALENZUELA, D., MURPHY, A. et al. (2007). Mammalian Sir2 homolog SIRT3 regulates global mitochondrial lysine acetylation. $\mathrm{Mol}$ Cell Biol 27: 8807-8814.

LONGO, V.D. and KENNEDY, B.K. (2006). Sirtuins in aging and age-related disease. Cell 126: 257-268.

LOPEZ-RUBIO, J.J., GONTIJO, A.M., NUNES, M.C., ISSAR, N., HERNANDEZ RIVAS, R. and SCHERF, A. (2007). 5' flanking region of var genes nucleate histone modification patterns linked to phenotypic inheritance of virulence traits in malaria parasites. Mol Microbiol 66: 1296-1305.

LUIJSTERBURG, M.S., WHITE, M.F., VAN DRIEL, R. and DAME R.T. (2008). The major architects of chromatin: architectural proteins in bacteria, archaea and eukaryotes. Crit Rev Biochem Mol Biol 43: 393-418.

LUO, J., NIKOLAEV, A.Y., IMAI, S., CHEN, D., SU, F., SHILOH, A., GUARENTE, L. and GU, W. (2001). Negative control of p53 by Sir2alpha promotes cell survival under stress. Cell 107: 137-148.

MA, W., STAFFORD, L.J., LI, D., LUO, J., LI, X., NING, G. and LIU, M. (2007). GCIP/ CCNDBP1, a helix-loop-helix protein, suppresses tumorigenesis. JCellBiochem 100: $1376-1386$

MAAS, N.L., MILLER, K.M., DEFAZIO, L.G. and TOCZYSKI, D.P. (2006). Cell cycle and checkpoint regulation of histone $\mathrm{H} 3 \mathrm{~K} 56$ acetylation by $\mathrm{Hst} 3$ and $\mathrm{Hst} 4$. Mol Cell 23: 109-119.

MARGUERON, R., TROJER, P. and REINBERG, D. (2005). The key to development: interpreting the histone code? Curr Opin Genet Dev 15: 163-176.

MARSTON, A.L., LEE, B.H. and AMON, A. (2003). The Cdc14 phosphatase and the FEAR network control meiotic spindle disassembly and chromosome segregation. Dev Cell 4: 711-726.

MASUMOTO, H., HAWKE, D., KOBAYASHI, R. and VERREAULT, A. (2005). A role for cell-cycle-regulated histone $\mathrm{H} 3$ lysine 56 acetylation in the DNA damage response. Nature 436: 294-298.

MCBURNEY, M.W., YANG, X., JARDINE, K., BIEMAN, M., TH'NG, J. and LEMIEUX, M. (2003a). The absence of SIR2alpha protein has no effect on global gene silencing in mouse embryonic stem cells. Mol Cancer Res 1: 402-409.

MCBURNEY, M.W., YANG, X., JARDINE, K., HIXON, M., BOEKELHEIDE, K., WEBB, J.R., LANSDORP, P.M. and LEMIEUX, M. (2003b). The mammalian SIR2alpha protein has a role in embryogenesis and gametogenesis. Mol Cell Biol 23: 38-54.

MEEHAN, R.R., KAO, C.F. and PENNINGS, S. (2003). HP1 binding to native chromatin in vitrois determined by the hinge region and not by the chromodomain. EMBO J 22: 3164-3174.

MELLONE, B.G., BALL, L., SUKA, N., GRUNSTEIN, M.R., PARTRIDGE, J.F. and ALLSHIRE, R.C. (2003). Centromere silencing and function in fission yeast is governed by the amino terminus of histone H3. Curr Biol 13: 1748-1757.

MERRICK, C.J. and DURAISINGH, M.T. (2006). Heterochromatin-mediated control of virulence gene expression. Mol Microbiol 62: 612-20.

MERRICK, C.J. and DURAISINGH, M.T. (2007). Plasmodium falciparum Sir2: an unusual sirtuin with dual histone deacetylase and ADP-ribosyltransferase activity. Eukaryot Cell 6: 2081-2091.

MICHISHITA, E., PARK, J.Y., BURNESKIS, J.M., BARRETT, J.C. and HORIKAWA, I. (2005). Evolutionarily Conserved and Nonconserved Cellular Localizations and Functions of Human SIRT Proteins. Mol Biol Cell 16: 4623-4635. 
MICHISHITA, E., MCCORD, R.A., BERBER, E., KIOI, M., PADILLA-NASH, H., DAMIAN, M., CHEUNG, P., KUSUMOTO, R., KAWAHARA, T.L., BARRETT, J.C. et al. (2008). SIRT6 is a histone H3 lysine 9 deacetylase that modulates telomeric chromatin. Nature 452: 492-496.

MILLS, K.D., SINCLAIR, D.A. and GUARENTE, L. (1999). MEC1-dependent redistribution of the $\mathrm{Sir} 3$ silencing protein from telomeres to DNA double-strand breaks. Cell 97: 609-620.

MIN, J., LANDRY, J., STERNGLANZ, R. and XU, R.M. (2001). Crystal structure of a SIR2 homolog-NAD complex. Cell 105: 269-279.

MIN, J., ZHANG, X., CHENG, X., GREWAL, S.I. and XU, R.M. (2002). Structure of the SET domain histone lysine methyltransferase Clr4. Nat Struct Biol 9: 828832.

MOAZED, D., KISTLER, A., AXELROD, A., RINE, J. and JOHNSON, A.D. (1997). Silent information regulator protein complexes in Saccharomyces cerevisiae: a SIR2/SIR4 complex and evidence for a regulatory domain in SIR4 that inhibits its interaction with SIR3. Proc Natl Acad Sci USA 94: 2186-2191.

MOSTOSLAVSKY, R., CHUA, K.F., LOMBARD, D.B., PANG, W.W., FISCHER, M.R., GELLON, L., LIU, P., MOSTOSLAVSKY, G., FRANCO, S., MURPHY, M.M. et al. (2006). Genomic instability and aging-like phenotype in the absence of mammalian SIRT6. Cell 124: 315-329.

MOtTA, M.C., DIVECHA, N., LEMIEUX, M., KAMEL, C., CHEN, D., GU, W., BULTSMA, Y., MCBURNEY, M. and GUARENTE, L. (2004). Mammalian SIRT1 represses forkhead transcription factors. Cell 116: 551-563.

MOYNIHAN, K.A., GRIMM, A.A., PLUEGER, M.M., BERNAL-MIZRACHI, E., FORD, E., CRAS-MENEUR, C., PERMUTT, M.A. and IMAI, S. (2005). Increased dosage of mammalian Sir2 in pancreatic beta cells enhances glucosestimulated insulin secretion in mice. Cell Metab 2: 105-117.

MURAYAMA, A., OHMORI, K., FUJIMURA, A., MINAMI, H., YASUZAWA-TANAKA, K., KURODA, T., OIE, S., DAITOKU, H., OKUWAKI, M., NAGATA, K., FUKAMIZU, A., KIMURA, K., SHIMIZU, T. and YANAGISAWA, J. (2008). Epigenetic control of rDNA loci in response to intracellular energy status. Cell 133:627-639.

MUTH, V., NADAUD, S., GRUMMT, I. and VOIT, R. (2001). Acetylation of TAF (I)68, a subunit of TIF-IB/SL1, activates RNA polymerase I transcription. EMBO J 20: 1353-1362.

NAKAMURA, Y., OGURA, M., TANAKA, D. and INAGAKI, N. (2008). Localization of mouse mitochondrial SIRT proteins: shift of SIRT3 to nucleus by coexpression with SIRT5. Biochem Biophys Res Commun 366: 174-179.

NARALA, S.R., ALLSOPP, R.C., WELLS, T.B., ZHANG, G., PRASAD, P., COUSSENS, M.J., ROSSI, D.J., WEISSMAN, I.L. and VAZIRI, H. (2008). SIRT1 Acts as a Nutrient-sensitive Growth Suppressor and Its Loss Is Associated with Increased AMPK and Telomerase Activity. Mol Biol Cell 19: 12101219.

NEWMAN, B.L., LUNDBLAD, J.R., CHEN, Y. and SMOLIK, S.M. (2002). A Drosophila homologue of Sir2 modifies position-effect variegation but does not affect life span. Genetics 162: 1675-1685.

NG, H.H., FENG, Q., WANG, H., ERDJUMENT-BROMAGE, H., TEMPST, P., ZHANG, Y. and STRUHL, K. (2002). Lysine methylation within the globular domain of histone $\mathrm{H} 3$ by Dot 1 is important for telomeric silencing and Sir protein association. Genes Dev 16: 1518-1527.

NIELSEN, A.L., OULAD-ABDELGHANI, M., ORTIZ, J.A., REMBOUTSIKA, E., CHAMBON, P. and LOSSON, R. (2001a). Heterochromatin formation in mammalian cells: interaction between histones and HP1 proteins. Mol Cell 7: 729739.

NIELSEN, S.J., SCHNEIDER, R., BAUER, U.M., BANNISTER, A.J., MORRISON, A., O'CARROLL, D., FIRESTEIN, R., CLEARY, M., JENUWEIN, T., HERRERA, R.E. et al. (2001b). Rb targets histone $\mathrm{H} 3$ methylation and HP1 to promoters. Nature 412: 561-565.

NORTH, B.J., MARSHALL, B.L., BORRA, M.T., DENU, J.M. and VERDIN, E. (2003). The human Sir2 ortholog, SIRT2, is an NAD+-dependent tubulin deacetylase. Mol Cell 11: 437-444.

NORTH, B.J., SCHWER, B., AHUJA, N., MARSHALL, B. and VERDIN, E. (2005). Preparation of enzymatically active recombinant class III protein deacetylases. Methods 36: 338-345.

NORTH, B.J. and VERDIN, E. (2007a). Interphase nucleo-cytoplasmic shuttling and localization of SIRT2 during mitosis. PLOS ONE 2: e784.

NORTH, B.J. and VERDIN, E. (2007b). Mitotic regulation of SIRT2 by cyclin- dependent kinase 1-dependent phosphorylation. J Biol Chem 282: 1954619545.

OBERDOERFFER, P., MICHAN, S., MCVAY, M., MOSTOSLAVSKY, R., VANN, J., PARK, S.K., HARTLERODE, A., STEGMULLER, J., HAFNER, A., LOERCH, P., WRIGHT, S.M., MILLS, K.D., BONNI, A., YANKNER, B.A., SCULLY, R., PROLLA, T.A., ALT, F.W. and SINCLAIR, D.A. (2008). SIRT1 redistribution on chromatin promotes genomic stability but alters gene expression during aging Cell 135: 907-918.

O'CARROLL, D., SCHERTHAN, H., PETERS, A.H., OPRAVIL, S., HAYNES, A.R. LAIBLE, G., REA, S., SCHMID, M., LEBERSORGER, A., JERRATSCH, M. et al. (2000). Isolation and characterization of Suv39h2, a second histone H3 methyltransferase gene that displays testis-specific expression. Mol Cell Biol 20: 9423-9433.

O'HAGAN, H.M., MOHAMMAD, H.P. and BAYLIN, S.B. (2008).. Double strand breaks can initiate gene silencing and SIRT1-dependent onset of DNA methylation in an exogenous promoter CpG island. PLoS Genet 4: e1000155.

ONYANGO, P., CELIC, I., MCCAFFERY, J.M., BOEKE, J.D. and FEINBERG, A.P (2002). SIRT3, a human SIR2 homologue, is an NAD-dependent deacetylase localized to mitochondria. Proc Natl Acad Sci USA 99: 13653-13658.

OUTEIRO, T.F., KONTOPOULOS, E., ALTMANN, S.M., KUFAREVA, I., STRATHEARN, K.E., AMORE, A.M., VOLK, C.B., MAXWELL, M.M., ROCHET, J.C., MCLEAN, P.J. et al. (2007). Sirtuin 2 inhibitors rescue alpha-synucleinmediated toxicity in models of Parkinson's disease. Science 317: 516-519.

PARSEGHIAN, M.H., NEWCOMB, R.L., WINOKUR, S.T. and HAMKALO, B.A (2000). The distribution of somatic $\mathrm{H} 1$ subtypes is non-random on active vs. inactive chromatin: distribution in human fetal fibroblasts. Chromosome Res 8 : 405-424.

PARSEGHIAN, M.H., NEWCOMB, R.L. and HAMKALO, B.A. (2001). Distribution of somatic $\mathrm{H} 1$ subtypes is non-random on active vs. inactive chromatin II: distribution in human adult fibroblasts. J Cell Biochem 83: 643-659.

PERROD, S., COCKELL, M.M., LAROCHE, T., RENAULD, H., DUCREST, A.L., BONNARD, C. and GASSER, S.M. (2001). A cytosolic NAD-dependent deacetylase, Hst2p, can modulate nucleolar and telomeric silencing in yeast. EMBO J 20: 197-209.

PETERS, A.H., O'CARROLL, D., SCHERTHAN, H., MECHTLER, K., SAUER, S. SCHOFER, C., WEIPOLTSHAMMER, K., PAGANI, M., LACHNER, M., KOHLMAIER, A. et al. (2001). Loss of the Suv39h histone methyltransferases impairs mammalian heterochromatin and genome stability. Cell 107: 323-337.

PICARD, F., KURTEV, M., CHUNG, N., TOPARK-NGARM, A., SENAWONG, T. MACHADO DE OLIVEIRA, R., LEID, M., MCBURNEY, M.W. and GUARENTE, L. (2004a). Sirt1 promotes fat mobilization in white adipocytes by repressing PPAR-gamma. Nature 429: 771-776.

PICARD, F., KURTEV, M., CHUNG, N., TOPARK-NGARM, A., SENAWONG, T., OLIVEIRA, R.M., LEID, M., MCBURNEY, M.W. and GUARENTE, L. (2004b). Sirt1 promotes fat mobilization in white adipocytes by repressing PPARgamma. Nature 429: 771-776.

PIEPER, A.A., BLACKSHAW, S., CLEMENTS, E.E., BRAT, D.J., KRUG, D.K., WHITE, A.J., PINTO-GARCIA, P., FAVIT, A., CONOVER, J.R., SNYDER, S.H. et al. (2000). Poly (ADP-ribosyl)ation basally activated by DNA strand breaks reflects glutamate-nitric oxide neurotransmission. Proc Natl Acad Sci USA 97 1845-1850.

PIJNAPPEL, W.W., SCHAFT, D., ROGUEV, A., SHEVCHENKO, A., TEKOTTE, H., WILM, M., RIGAUT, G., SERAPHIN, B., AASLAND, R. and STEWART, A.F. (2001). The S. cerevisiae SET3 complex includes two histone deacetylases, Hos2 and Hst1, and is a meiotic-specific repressor of the sporulation gene program. Genes Dev 15: 2991-3004.

PIPERNO, G., LEDIZET, M. and CHANG, X.J. (1987). Microtubules containing acetylated alpha-tubulin in mammalian cells in culture. J Cell Bio/ 104: 289-302.

POTHOF, J., VAN HAAFTEN, G., THIJSSEN, K., KAMATH, R.S., FRASER, A.G. AHRINGER, J., PLASTERK, R.H. and TIJSTERMAN, M. (2003). Identification of genes that protect the $C$. elegans genome against mutations by genome-wide RNAi. Genes Dev 17: 443-448.

PROZOROVSKI, T., SCHULZE-TOPPHOFF, U., GLUMM, R., BAUMGART, J., SCHROTER, F., NINNEMANN, O., SIEGERT, E., BENDIX, I., BRUSTLE, O., NITSCH, R. et al. (2008). Sirt1 contributes critically to the redox-dependent fate of neural progenitors. Nat Cell Biol 10: 385-394.

PRUITT, K., ZINN, R.L., OHM, J.E., MCGARVEY, K.M., KANG, S.H., WATKINS, 
D.N., HERMAN, J.G. and BAYLIN, S.B. (2006). Inhibition of SIRT1 reactivates silenced cancer genes without loss of promoter DNA hypermethylation. PLoS Genet 2: e40.

REA, S., EISENHABER, F., O'CARROLL, D., STRAHL, B.D., SUN, Z.W., SCHMID, M., OPRAVIL, S., MECHTLER, K., PONTING, C.P., ALLIS, C.D. et al. (2000). Regulation of chromatin structure by site-specific histone $\mathrm{H} 3$ methyltransferases. Nature 406: 593-599.

RINE, J., STRATHERN, J.N., HICKS, J.B. and HERSKOWITZ, I. (1979). A suppressor of mating-type locus mutations in Saccharomyces cerevisiae: evidence for and identification of cryptic mating-type loci. Genetics 93: 877-901.

RINE, J. and HERSKOWITZ, I. (1987). Four genes responsible for a position effect on expression from HML and HMR in Saccharomyces cerevisiae. Genetics 116: 9-22.

ROBERT, F., POKHOLOK, D.K., HANNETT, N.M., RINALDI, N.J., CHANDY, M., ROLFE, A., WORKMAN, J.L., GIFFORD, D.K. and YOUNG, R.A. (2004). Global position and recruitment of HATs and HDACs in the yeast genome. Mol Cell 16: 199-209.

ROBYR, D., SUKA, Y., XENARIOS, I., KURDISTANI, S.K., WANG, A., SUKA, N. and GRUNSTEIN, M. (2002). Microarray deacetylation maps determine genome-wide functions for yeast histone deacetylases. Cell 109: 437-446.

RODGERS, J.T., LERIN, C., HAAS, W., GYGI, S.P., SPIEGELMAN, B.M. and PUIGSERVER, P. (2005). Nutrient control of glucose homeostasis through a complex of PGC-1alpha and SIRT1. Nature 434: 113-118.

ROGINA, B., HELFAND, S.L. and FRANKEL, S. (2002). Longevity regulation by Drosophila Rpd3 deacetylase and caloric restriction. Science 298: 1745.

ROGINA, B. and HELFAND, S.L. (2004). Sir2 mediates longevity in the fly through a pathway related to calorie restriction. Proc Natl Acad Sci USA 101: 1599816003.

ROSE, G., DATO, S., ALTOMARE, K., BELLIZZI, D., GARASTO, S., GRECO, V., PASSARINO, G., FERACO, E., MARI, V., BARBI, C. et al. (2003). Variability of the SIRT3 gene, human silent information regulator Sir2 homologue, and survivorship in the elderly. Exp Gerontol 38: 1065-1070.

ROSENBERG, M.I. and PARKHURST, S.M. (2002). Drosophila Sir2 is required for heterochromatic silencing and by euchromatic Hairy/E (Spl) bHLH repressors in segmentation and sex determination. Cell 109: 447-458

SAN-SEGUNDO, P.A. and ROEDER, G.S. (1999). Pch2 links chromatin silencing to meiotic checkpoint control. Cell 97: 313-324.

SANDMAN, K. and REEVE, J.N. (2005). Archaeal chromatin proteins: different structures but common function? Curr Opin Microbiol 8: 656-661.

SASAKI, T., MAIER, B., BARTKE, A. and SCRABLE, H. (2006). Progressive loss of SIRT1 with cell cycle withdrawal. Aging Cell 5: 413-422.

SAUNDERS, L.R. and VERDIN, E. (2007). Sirtuins: critical regulators at the crossroads between cancer and aging. Oncogene 26: 5489-5504.

SAUVE, A.A., CELIC, I., AVALOS, J., DENG, H., BOEKE, J.D. and SCHRAMM, V.L. (2001). Chemistry of gene silencing: the mechanism of NAD+-dependent deacetylation reactions. Biochemistry 40: 15456-15463.

SAUVE, A.A. and SCHRAMM, V.L. (2003). Sir2 regulation by nicotinamide results from switching between base exchange and deacetylation chemistry. Biochemistry 42: 9249-9256.

SCHER, M.B., VAQUERO, A. and REINBERG, D. (2007). SirT3 is a nuclear NAD+dependent histone deacetylase that translocates to the mitochondria upon cellular stress. Genes Dev 21: 920-928.

SCHERF, A., HERNANDEZ-RIVAS, R., BUFFET, P., BOTTIUS, E., BENATAR, C., POUVELLE, B., GYSIN, J. and LANZER, M. (1998). Antigenic variation in malaria: in situ switching, relaxed and mutually exclusive transcription of var genes during intra-erythrocytic development in Plasmodium falciparum. EMBO J 17: 5418-5426.

SCHOTTA, G., EBERT, A., KRAUSS, V., FISCHER, A., HOFFMANN, J., REA, S., JENUWEIN, T., DORN, R. and REUTER, G. (2002). Central role of Drosophila SU (VAR)3-9 in histone H3-K9 methylation and heterochromatic gene silencing. EMBO J 21: 1121-1131.

SCHWER, B., NORTH, B.J., FRYE, R.A., OTT, M. and VERDIN, E. (2002). The human silent information regulator (Sir)2 homologue hSIRT3 is a mitochondria nicotinamide adenine dinucleotide-dependent deacetylase. J Cell Biol 158: 647-657.
SCHWER, B., BUNKENBORG, J., VERDIN, R.O., ANDERSEN, J.S. and VERDIN E. (2006). Reversible lysine acetylation controls the activity of the mitochondrial enzyme acetyl-CoA synthetase 2. Proc Natl Acad Sci USA 103: 10224-10229.

SHAHBAZIAN, M.D. and GRUNSTEIN, M. (2007). Functions of site-specific histone acetylation and deacetylation. Annu Rev Biochem 76: 75-100.

SHANKARANARAYANA, G.D., MOTAMEDI, M.R., MOAZED, D. and GREWAL, S.I. (2003). Sir2 regulates histone $\mathrm{H} 3$ lysine 9 methylation and heterochromatin assembly in fission yeast. Curr Biol 13: 1240-1246.

SHI, T., WANG, F., STIEREN, E. and TONG, Q. (2005). SIRT3, a mitochondrial sirtuin deacetylase, regulates mitochondrial function and thermogenesis in brown adipocytes. J Biol Chem 280: 13560-13567.

SHOGREN-KNAAK, M., ISHII, H., SUN, J.M., PAZIN, M.J., DAVIE, J.R. and PETERSON, C.L. (2006). Histone H4-K16 acetylation controls chromatin structure and protein interactions. Science 311: 844-847.

SHOU, W., SEOL, J.H., SHEVCHENKO, A., BASKERVILLE, C., MOAZED, D., CHEN, Z.W., JANG, J., CHARBONNEAU, H. and DESHAIES, R.J. (1999). Exit from mitosis is triggered by Tem1-dependent release of the protein phosphatase Cdc14 from nucleolar RENT complex. Cell 97: 233-244

SHOU, W., SAKAMOTO, K.M., KEENER, J., MORIMOTO, K.W., TRAVERSO E.E., AZZAM, R., HOPPE, G.J., FELDMAN, R.M., DEMODENA, J., MOAZED, D. et al. (2001). Net1 stimulates RNA polymerase I transcription and regulates nucleolar structure independently of controlling mitotic exit. Mol Cell 8: 45-55.

SINCLAIR, D., MILLS, K. and GUARENTE, L. (1998). Aging in Saccharomyces cerevisiae. Annu Rev Microbiol 52: 533-560.

STARAI, V.J., CELIC, I., COLE, R.N., BOEKE, J.D. and ESCALANTE-SEMERENA, J.C. (2002). Sir2-dependent activation of acetyl-CoA synthetase by deacetylation of active lysine. Science 298: 2390-2392.

STRAIGHT, A.F., SHOU, W., DOWD, G.J., TURCK, C.W., DESHAIES, R.J., JOHNSON, A.D. and MOAZED, D. (1999). Net1, a Sir2-associated nucleolar protein required for rDNA silencing and nucleolar integrity. Cell 97: 245-256.

SUKA, N., LUO, K. and GRUNSTEIN, M. (2002). Sir2p and Sas2p opposingly regulate acetylation of yeast histone $\mathrm{H} 4$ lysine 16 and spreading of heterochromatin. Nat Genet 32: 378-383.

TADDEI, A., MAISON, C., ROCHE, D. and ALMOUZNI, G. (2001). Reversible disruption of pericentric heterochromatin and centromere function by inhibiting deacetylases. Nat Cell Biol 3: 114-120.

TAIPALE, M., REA, S., RICHTER, K., VILAR, A., LICHTER, P., IMHOF, A. and AKHTAR, A. (2005). hMOF histone acetyltransferase is required for histone $\mathrm{H} 4$ lysine 16 acetylation in mammalian cells. Mol Cell Biol 25: 6798-6810.

TANNY, J.C., DOWD, G.J., HUANG, J., HILZ, H. and MOAZED, D. (1999). An enzymatic activity in the yeast Sir2 protein that is essential for gene silencing. Cell 99: 735-745.

TING, A.H., MCGARVEY, K.M. and BAYLIN, S.B. (2006). The cancer epigenomecomponents and functional correlates. Genes Dev 20: 3215-3231.

TISSENBAUM, H.A. and GUARENTE, L. (2001). Increased dosage of a sir-2 gene extends lifespan in Caenorhabditis elegans. Nature 410: 227-230.

TREMETHICK, D.J. (2007). Higher-order structures of chromatin: the elusive $30 \mathrm{~nm}$ fiber. Cell 128: 651-654.

TROJER, P., LI, G., SIMS, R.J., 3RD, VAQUERO, A., KALAKONDA, N., BOCCUNI, P., LEE, D., ERDJUMENT-BROMAGE, H., TEMPST, P., NIMER, S.D. et al. (2007). L3MBTL1, a histone-methylation-dependent chromatin lock. Cell 129 915-928.

TROJER, P. and REINBERG, D. (2007). Facultative heterochromatin: is there a distinctive molecular signature? Mol Cell 28: 1-13.

TSANG, A.W. and ESCALANTE-SEMERENA, J.C. (1998). CobB, a new member of the SIR2 family of eucaryotic regulatory proteins, is required to compensate for the lack of nicotinate mononucleotide:5,6-dimethylbenzimidazole phosphoribosyltransferase activity in cobT mutants during cobalamin biosynthesis in Salmonella typhimurium LT2. J Biol Chem 273: 31788-31794.

VAKHRUSHEVA, O., SMOLKA, C., GAJAWADA, P., KOSTIN, S., BOETTGER, T., KUBIN, T., BRAUN, T. and BOBER, E. (2008) Sirt7 increases stress resistance of cardiomyocytes and prevents apoptosis and inflammatory cardiomyopathy in mice. Circ Res 102: 703-710.

VAN DER HORST, A., TERTOOLEN, L.G., DE VRIES-SMITS, L.M., FRYE, R.A., MEDEMA, R.H. and BURGERING, B.M. (2004). FOXO4 is acetylated upon 


\section{A. Vaquero et al.}

peroxide stress and deacetylated by the longevity protein hSir2(SIRT1). J Biol Chem 279: 28873-28879.

VAQUERO, A., LOYOLA, A. and REINBERG, D. (2003). The constantly changing face of chromatin. Sci Aging Knowledge Environ 2003: RE4.

VAQUERO, A., SCHER, M., LEE, D., ERDJUMENT-BROMAGE, H., TEMPST, P. and REINBERG, D. (2004). Human SirT1 interacts with histone $\mathrm{H} 1$ and promotes formation of facultative heterochromatin. Mol Cell 16: 93-105.

VAQUERO, A., SCHER, M.B., LEE, D.H., SUTTON, A., CHENG, H.L., ALT, F.W., SERRANO, L., STERNGLANZ, R. and REINBERG, D. (2006). SirT2 is a histone deacetylase with preference for histone H4 Lys 16 during mitosis. Genes Dev 20: $1256-1261$.

VAQUERO, A., SCHER, M., ERDJUMENT-BROMAGE, H., TEMPST, P., SERRANO, L. and REINBERG, D. (2007a). SIRT1 regulates the histone methyl-transferase SUV39H1 during heterochromatin formation. Nature 450: 440-444.

VAQUERO, A., STERNGLANZ, R. and REINBERG, D. (2007b). NAD+-dependent deacetylation of $\mathrm{H} 4$ lysine 16 by class III HDACs. Oncogene 26: 5505-5520.

VAUTE, O., NICOLAS, E., VANDEL, L. and TROUCHE, D. (2002). Functional and physical interaction between the histone methyl transferase Suv39H1 and histone deacetylases. Nucleic Acids Res 30: 475-481.

VAZIRI, H., DESSAIN, S.K., NG EATON, E., IMAI, S.I., FRYE, R.A., PANDITA, T.K., GUARENTE, L. and WEINBERG, R.A. (2001). hSIR2(SIRT1) functions as an NAD-dependent p53 deacetylase. Cell 107: 149-159.

VERDIN, E., DEQUIEDT, F. and KASLER, H.G. (2003). Class II histone deacetylases: versatile regulators. Trends Genet 19: 286-293.

VERGNES, B., SERENO, D., MADJIDIAN-SERENO, N., LEMESRE, J.L. and OUAISSI, A. (2002). Cytoplasmic SIR2 homologue overexpression promotes survival of Leishmania parasites by preventing programmed cell death. Gene 296: 139-150.

VERGNES, B., SERENO, D., TAVARES, J., CORDEIRO-DA-SILVA, A., VANHILLE, L., MADJIDIAN-SERENO, N., DEPOIX, D., MONTE-ALEGRE, A. and OUAISSI, A. (2005). Targeted disruption of cytosolic SIR2 deacetylase discloses its essential role in Leishmania survival and proliferation. Gene 363: 85-96.

VIRE, E., BRENNER, C., DEPLUS, R., BLANCHON, L., FRAGA, M., DIDELOT, C., MOREY, L., VAN EYNDE, A., BERNARD, D., VANDERWINDEN, J.M. et al. (2006). The Polycomb group protein EZH2 directly controls DNA methylation. Nature 439: 871-874.

VISWANATHAN, M., KIM, S.K., BERDICHEVSKY, A. and GUARENTE, L. (2005). A role for SIR-2.1 regulation of ER stress response genes in determining $C$. elegans life span. Dev Cell 9: 605-615.
WANG, C., CHEN, L., HOU, X., LI, Z., KABRA, N., MA, Y., NEMOTO, S., FINKEL, T., GU, W., CRESS, W.D. et al. (2006). Interactions between E2F1 and SirT1 regulate apoptotic response to DNA damage. Nat Cell Biol 8: 1025-1031.

WARDLEWORTH, B.N., RUSSELL, R.J., BELL, S.D., TAYLOR, G.L. and WHITE, M.F. (2002). Structure of Alba: an archaeal chromatin protein modulated by acetylation. EMBO J 21: 4654-4662.

WILSON, J.M., LE, V.Q., ZIMMERMAN, C., MARMORSTEIN, R. and PILLUS, L. (2006). Nuclear export modulates the cytoplasmic Sir2 homologue Hst2. EMBO Rep 7: 1247-1251.

WONG, S. and WEBER, J.D. (2007). Deacetylation of the retinoblastoma tumour suppressor protein by SIRT1. Biochem J 407: 451-460.

WU, J. and GRUNSTEIN, M. (2000). 25 years after the nucleosome model: chromatin modifications. Trends Biochem Sci 25: 619-623.

XIE, J., PIERCE, M., GAILUS-DURNER, V., WAGNER, M., WINTER, E. and VERSHON, A.K. (1999). Sum1 and Hst1 repress middle sporulation-specific gene expression during mitosis in Saccharomyces cerevisiae. EMBO $J$ 18: 6448-6454.

XU, F., ZHANG, Q., ZHANG, K., XIE, W. and GRUNSTEIN, M. (2007). Sir2 deacetylates histone $\mathrm{H} 3$ lysine 56 to regulate telomeric heterochromatin structure in yeast. Mol Cell 27: 890-900.

YAMAMOTO, H., SCHOONJANS, K. and AUWERX, J. (2007). Sirtuin functions in health and disease. Mol Endocrinol 21: 1745-1755.

YANG, X.J. and SETO, E. (2008). The Rpd3/Hda1 family of lysine deacetylases: from bacteria and yeast to mice and men. Nat Rev Mol Cell Biol 9: 206-218.

YEUNG, F., HOBERG, J.E., RAMSEY, C.S., KELLER, M.D., JONES, D.R., FRYE, R.A. and MAYO, M.W. (2004). Modulation of NF-kappaB-dependent transcription and cell survival by the SIRT1 deacetylase. EMBO J 23: 2369-2380.

YOUNGER-SHEPHERD, S., VAESSIN, H., BIER, E., JAN, L.Y. and JAN, Y.N. (1992). deadpan, an essential pan-neural gene encoding an HLH protein, acts as a denominator in Drosophila sex determination. Cell 70: 911-922.

YUAN, Z., ZHANG, X., SENGUPTA, N., LANE, W.S. and SETO, E. (2007). SIRT1 regulates the function of the Nijmegen breakage syndrome protein. Mol Cell 27 149-162.

ZHAO, K., CHAI, X. and MARMORSTEIN, R. (2003). Structure of a Sir2 substrate, Alba, reveals a mechanism for deacetylation-induced enhancement of DNA binding. J Biol Chem 278: 26071-26077.

ZHAO, W., KRUSE, J.P., TANG, Y., JUNG, S.Y., QIN, J. and GU, W. (2008). Negative regulation of the deacetylase SIRT1 by DBC1. Nature 451: 587-590. 


\section{Further Related Reading, published previously in the Int. J. Dev. Biol.}

See our Special Issue Fertilization edited by Paul M. Wassarman and Victor D. Vacquier at: http://www.ijdb.ehu.es/web/contents.php?vol=52\&issue=5-6

New telomere formation during the process of chromatin diminution in Ascaris suum. Stephan Jentsch, Heinz Tobler and Fritz Müller

Int. J. Dev. Biol. (2002) 46: 143-148

Extensive conservation of sequences and chromatin structures in the bxd polycomb response element among Drosophilid species.

Gaetano I Dellino, Christophe Tatout and Vincenzo Pirrotta

Int. J. Dev. Biol. (2002) 46: 133-141

Multiple stage-dependent roles for histone deacetylases during amphibian embryogenesis: implications for the involvement of extracellular matrix remodeling. S Damjanovski, L M Sachs and Y B Shi Int. J. Dev. Biol. (2000) 44: 769-776

Characterisation of developmentally regulated chromatin structure in the coding region of the proto-oncogene, $\mathrm{c}$-fos, in the male laboratory mouse.

$C$ Kanduri and R Raman

Int. J. Dev. Biol. (1999) 43: 279-282

X-chromosome activity: impact of imprinting and chromatin structure.

R V Jamieson, P P Tam and M Gardiner-Garden

Int. J. Dev. Biol. (1996) 40: 1065-1080

2006 ISI ** Impact Factor $=3.577^{* *}$

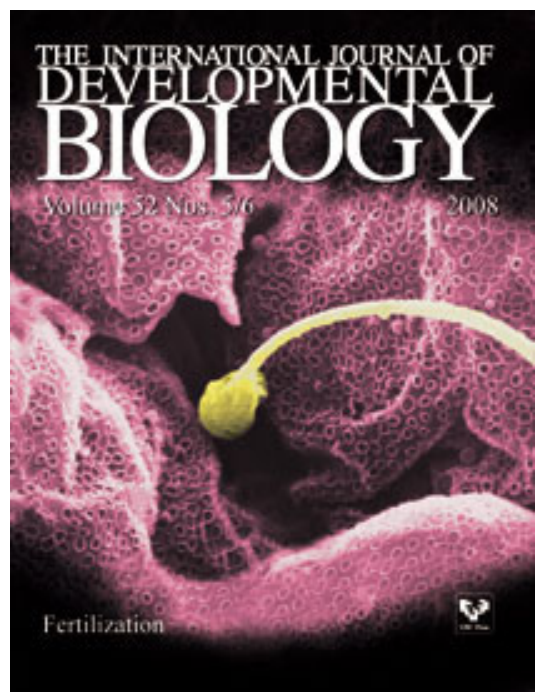

